\title{
Circulation on the Northwestern Iberian Margin:
} Swoddies

\author{
Ana Teles-Machado Álvaro Peliz James C. McWilliams \\ Jesus Dubert Bernard Le Cann
}

September 21, 2015

\begin{abstract}
We study the eddies that form by the destabilization of the Iberian Poleward Current. Some anticyclones have been identified in satellite Sea Surface Temperature, as they are persistent and remarkably warm, and they contain IPC waters in their core. The number of observed eddies is small, so not much is known about their statistics, places of formation, separation processes, and behavior away from the slope. In this study, the output of a 20-year high-resolution simulation is analyzed to study the formation of anticyclonic and cyclonic eddies by the destabilization of the Iberian Poleward Current, using an automatic eddy detection algorithm. The model reproduces the formation of some of the eddies at the same time and place, and with similar sizes as observed in satellite SST, although it is not able to reproduce their observed trajectories as they propagate away from the slope. We found there are distinct layers in the vertical, with different characteristics in terms of relative vorticity distribution. The top $200 \mathrm{~m}$ of the water column has an anticyclonic dominance, with stronger anticyclones; in the layer between 200 and $600 \mathrm{~m}$ depth the dominance is cyclonic, with more and stronger cyclones; and from 600 to $1000 \mathrm{~m}$ there is again an anticyclonic dominance, with more and stronger anticyclones than cyclones. The results show that the cyclones form mainly where topographic contours veer cyclonically in the poleward direction, while the anticyclones tend to form in places where topographic contours veer anticyclonically. We found there is a relationship of eddies formation with the wind variability. A sudden decrease in southerly winds, results in the development of instabilities in the IPC and formation of eddies. The shedding of the surface intensified anticyclones is accompanied by the shedding of deeper layer cyclones. In general the deep cyclones spin down faster than the surface anticyclones; anticyclones are generally tracked, and conserve their maximum relative
\end{abstract}

1

(C) 2015. This manuscript version is made available under the Elsevier user license http://www.elsevier.com/open-access/userlicense/1.0/ 
vorticity, for longer periods. The vertical structure of these surface intensified anticyclones, at the moment of formation, extends to deeper than $1200 \mathrm{~m}$, and this vertical extent decreases with time. They can survive winter deep convection that homogenizes their core.

Keywords: Oceanic Eddies; Slope currents; Northwestern Iberia; Oceanatmosphere system

\section{Introduction}

The Iberian Poleward Current (IPC) dominates the winter circulation over the upper slope and outer shelf of the Western Iberian Margin. This current is described in observational and numerical studies (Frouin et al., 1990; Martins et al., 2002; Peliz et al., 2003a,b, 2005; Torres and Barton, 2006; Friocourt et al., 2007, 2008b,a). The summer is dominated by upwellingtype shelf circulation with associated equatorward surface currents (Haynes et al., 1993; Relvas and Barton, 2002; Peliz et al., 2002). A description of the seasonal cycle is presented in Teles-Machado et al. (2015b): the IPC starts developing as an undercurrent with a core at around $200 \mathrm{~m}$ depth during late summer. By this time, the shelf and upper slope are still occupied by the southward flowing upwelling jet. Starting from December, average winds change from northerly to southwesterly promoting poleward flow over the shelf and upper slope. During these months, under favorable wind conditions, the IPC core migrates vertically, from the shelf break depths to the surface, becoming a surface intensified jet. Below, an equatorward flow denominated by Underslope Countercurrent (USCC), is present in model simulations (Teles-Machado et al., 2015b) and was observed in some cross-slope density sections (Oliveira et al., 2004). This equatorward flow is centered at $400 \mathrm{~m}$ depth, and extends from 200-300 $\mathrm{m}$ to $600 \mathrm{~m}$ (depending on the month). The IPC extends to the northern coast of the Iberian Peninsula, usually in December or January, as a narrow surface-intensified current noticeable for its warm Sea Surface Temperature (SST) signature all along the northern Iberian Margin (Pingree and Le Cann, 1990, 1992b; Friocourt et al., 2008b; Le Cann and Serpette, 2009). Pingree and Le Cann (1992a) named this warm water intrusion in the north coast Navidad. From February to May, the IPC weakens and part of it propagates offshore (Teles-Machado et al., 2015b).

Eddies formed by the destabilization of the IPC were first described in Pingree and Le Cann (1992b). The authors identified 3 anticyclonic eddies in satellite SST images, persistent and remarkably warm, and named them 
"Anticyclonic Slope Water Oceanic eDDIES" (Anticyclonic SWODDIES). All of these 3 eddies were observed in the Bay of Biscay (Fig. 1) in the winter of 1989/1990, characterized by a strong IPC (Garcia-Soto et al., 2002; TelesMachado et al., 2015a): one eddy (O90) formed to the east of Cape Ortegal (Fig. 1), and the other two (F90a,F90b) formed near the northern situated Cape Ferret (not shown). F90a was observed in-situ during the following summer and it had a homogeneous core of water in the center, a radius of approximately $40 \mathrm{~km}$, and maximum velocity at $100 \mathrm{~m}$ depth; its presence was felt as deep as $1800 \mathrm{~m}$ depth. Later, other eddies were observed in the Bay of Biscay: Pingree and Le Cann (1992a) identified one in May 1991 with an unknown place of formation, although the fact that its core was colder than F90 suggests that it could have formed further north; Garcia-Soto et al. (2002), in cloud-free satellite SST images, detected various Swoddies in the southeast corner of the Bay of Biscay, in the Januaries of 1990 and 1996. Both years also correspond to periods of strong IPC (Garcia-Soto et al., 2002; Teles-Machado et al., 2015a).

Swoddies also form and detach from the slope on the Iberian west coast. One anticyclonic Swoddy was observed in-situ at $41-42^{\circ} \mathrm{N}$, in May of 1993 (Fiúza et al., 1998); another was observed at 40.5-40.9 ${ }^{\circ}$ N, in February 2000 (Oliveira et al., 2004). Peliz et al. (2003b, 2005) also describes Swoddies forming on the west coast, detected in satellite SST images, in January and February of 1997, February of 1998, and January of 2002.

Dubert (1998) present an idealized model configuration of the IPC where a meridional density gradient interacts with the slope, in order to understand the mechanisms of Swoddies formation. This study analyzes the interaction of the current along the northern Iberian coast, with a cape similar to Cape Ortegal (Fig. 1). The results show that eddies detach upstream of the cape, as a dipolar structure where anticyclones have a companion cyclone, and also that bottom stress is important for the anticyclone formation, as it generates anticyclonic vorticity on the inshore side of the jet. Peliz et al. (2003b) also use an idealized model configuration, forced by meridional density gradients, but for the west coast. The study shows that anticyclones form in the lee of the main topographic features, by separation of the poleward slope flow, and remain trapped for periods of 2-3 months. Several cyclones develop around them, at deeper levels, by separation of the equatorward slope flow. These deep cyclones are important for the process of detachment of the anticyclones from the slope; when cyclones get strong enough, their circulation intensifies, pushing the anticyclones away from the slope in dipolar advection.

The Swoddies described in previous studies were mainly anticyclones, but since both cyclones and anticyclones can contain slope waters in their 
core, in this study we will refer to all of the eddies formed in the slope as Swoddies, and distinguish between cyclones and anticyclones. Despite the existence of various studies about the Swoddies, the number of observed eddies is small. The studies describe observations of sporadic eddies, at specific times, and not much is known about their statistics, places of formation, separation processes, and behavior away from the slope. In this study, the statistics and some details of this population of eddies is analyzed in a 20-year realistic model simulation, where eddies are identified using an automatic eddy detection algorithm. The next section describes the model, and the methods used for eddy detection. Section 3 shows some comparisons with observations. Section 4 describes the general characteristics of the eddies population. Section 5 presents a description, at the synoptic scales, of the Swoddies formation in the winter of 1989/1990, and of the time evolution of the vertical structure of three eddies. Finally, in section 6 , the results are summarized and discussed.

\section{Methods}

\subsection{Model Configuration}

The Regional Ocean Modeling System (ROMS) is used in a nested configuration. This simulation uses a larger domain (represented as A0 in Fig. 1) and an embedded child domain (represented as A1 in Fig. 1), running simultaneously and exchanging information between each other at every model time-step. The results presented here are from the higher resolution grid (grid A1 in Fig. 1) that has a resolution of 2.3 to $2.7 \mathrm{~km}\left(1 / 36^{\circ}\right)$. A0 has a resolution of 6.4 to $7.8 \mathrm{~km}\left(1 / 12^{\circ}\right)$. Both grids have 40 levels in the vertical with enhanced resolution near the surface to better resolve the boundary layer everywhere in the domain. The boundaries of the smaller grid (A1) do not have a classical numerical sponge, which would dissipate the structures, but 2-way nesting that allows a more continuous inter-facial behavior between the grids A1 and A0. The simulation spans the period of 1989 to 2008. The atmospheric forcing is obtained from a Weather Research and Forecast (WRF) simulation, at $27 \mathrm{~km}$ resolution, that is a downscaling of ERA-Interim reanalysis (Soares et al., 2012). The details of the ocean model configuration are described in Teles-Machado et al. (2015b) and TelesMachado et al. (2015a). 


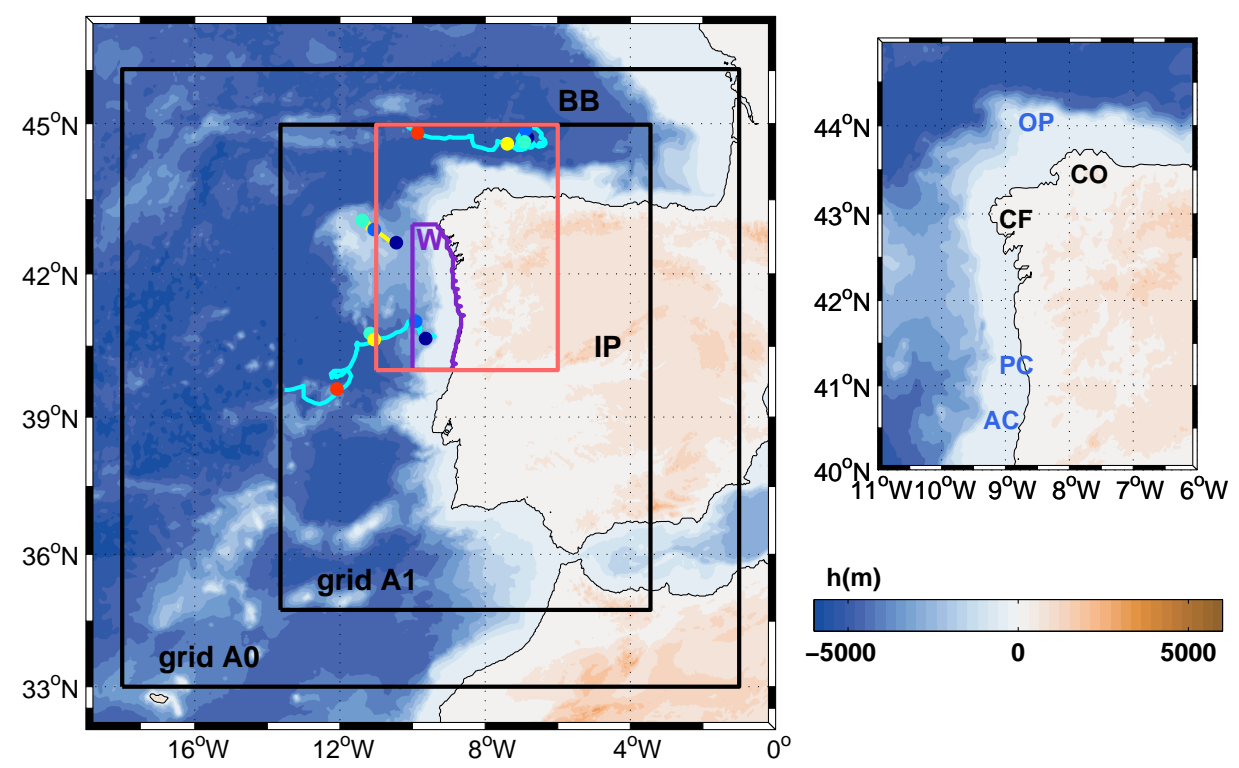

Figure 1: On the left: Map showing the 2 spatial domains used in the model configuration (Grids A0 and A1). The purple box $\mathrm{W}$ represents a domain on the western coast. Iberian Peninsula (IP) and Bay of Biscay (BB) are indicated in the map. Cyan (Yellow) lines represent the trajectories of 2 Anticyclones (1 Cyclone) (the dark blue dots indicate each eddy formation site, and the color dots represent specific dates, in the chronological order: dark blue, sea blue, cyan, yellow, red). On the right: a zoom on the slope area (salmon box on the left), described in the text, with indication of some topographic features: Cape Ortegal (CO), Ortegal Promontory (OP), Cape Finisterre (CF), Aveiro Canyon (AC) and Porto Canyon (PC). 


\subsection{Satellite SST}

We compare the model results with satellite SST AVHRR Pathfinder Version 5.2 (PFV5.2) data, obtained from the US National Oceanographic Data Center and GHRSST (http://pathfinder.nodc.noaa.gov) (Casey et al., 2010).

\subsection{Eddy Tracking Algorithm}

We use one automatic algorithm for eddy detection and tracking in the model outputs, developed by Nencioli et al. (2010). The algorithm detects eddies by analyzing the geometry of a $2 \mathrm{D}$ velocity vector field at a given depth level. The method was developed to analyze eddy activity from high resolution model simulations and has been used in various studies (Dong et al., 2012; Aguiar et al., 2013; Peliz et al., 2012). This algorithm starts by searching for a pair of zonal points where the meridional velocity reverses and increases away from the pair within $a$ grid points; then the same is done for the zonal velocity. The second step is to search for the velocity minimum in a square of width $2 b$, centered in one of the previously identified points. After identifying the eddy center, the algorithm checks that the velocity contours around the center have a constant sense of rotation. This algorithm slightly underestimates the eddy radius (Nencioli et al., 2010). The tracking algorithm was applied to the outputs of the grid A1 (Fig. 1). We use $a=4$ points and $b=3$ points, which after some tests showed to be the ones that provide the most successful detections. These values allow for the detection of eddies with a minimum radius of $6-9 \mathrm{~km}$.

\subsection{Eddy Tracking at 100 and $250 \mathrm{~m}$ Depths}

Given the fact that previous studies (Pingree and Le Cann, 1992b) indicate that anticyclonic Swoddies have maximum velocity signatures at around $100 \mathrm{~m}$ depth, the first eddy tracking is performed at this depth. Conversely, to capture the cyclones formed by the stretching of deeper layers (Peliz et al., 2003b), another tracking is done at $250 \mathrm{~m}$ depth. From all of the detected eddies, we select the ones that are tracked for at least 5 days, that are first detected north of $40^{\circ} \mathrm{N}$, near the slope (region represented in the zoom of Fig. 1), and within the period from October to March. This period is chosen in order to cover the months when the IPC is strongest and surface intensified - October to January - and also the months when it weakens and when the anomalies propagate offshore - January to March (Teles-Machado et al., 2015b). 
The detected eddies do not necessarily have their maximum azimuthal velocity at the detection depth. For example Meddies, which have the velocity maximum at deeper levels, can have a dynamical signature near the surface (Serra et al., 2010; Aguiar et al., 2013). To identify the level at which each eddy (from the detected population) has its maximum signature, we compute average profiles of relative vorticity at each eddy's center (averaging the profiles for the entire tracking period of each eddy) and search for its maximum at depth. Figure 2 (bottom) shows how many cyclones and anticyclones have the maximum at each depth, for the detections made at 100 and $250 \mathrm{~m}$ (left and right columns, respectively). In Fig. 2 (top), each eddy is represented as a function of the depth of maximum relative vorticity and its intensity. For detections made at both levels, eddies are intensified at a wide range of depths, from the surface down to deeper than $1200 \mathrm{~m}$. Different layers are distinguished, presenting eddy populations with different characteristics. These differences are analyzed in section 4 .

\section{Comparisons with Observations}

The model results were already compared with observations in Teles-Machado et al. (2015b) and Teles-Machado et al. (2015a) for the seasonal cycle and interannual variability, respectively. To evaluate the model skill in reproducing the correct eddy scales and types of structures that were observed, we compare the model with Pathfinder Satellite SST fields on the same days. We selected days with available cloud free SST satellite images, which showed the presence of a destabilized IPC. The comparisons are displayed in Figures 3, 4 and 5. The eddies identified with the eddy tracking at $100 \mathrm{~m}$ depth, which have their maximum relative vorticity in the top $200 \mathrm{~m}$ of the water column, are superimposed on both model and satellite SST fields.

Figure 3 shows 3 snapshots of the strong IPC event of the winter of 1989/1990 (Garcia-Soto et al., 2002; Teles-Machado et al., 2015a). During this year various Swoddies were observed by satellite and in-situ data on the northern coast, as described in the introduction (Pingree and Le Cann, 1992b,a). Despite the turbulent nature of these processes, some of the structures that were observed are reproduced in the model in great detail and in phase with reality. For example, on the 29 of December of 1989 (top Fig. 3), the model shows a mesoscale field with the same kind of structures observed in the SST on the northern coast. A perturbation developing north of Cape Ortegal (Fig. 1) is visible both on the satellite and model SST fields. This feature is coincident with the presence of an anticyclonic Swoddy detected 

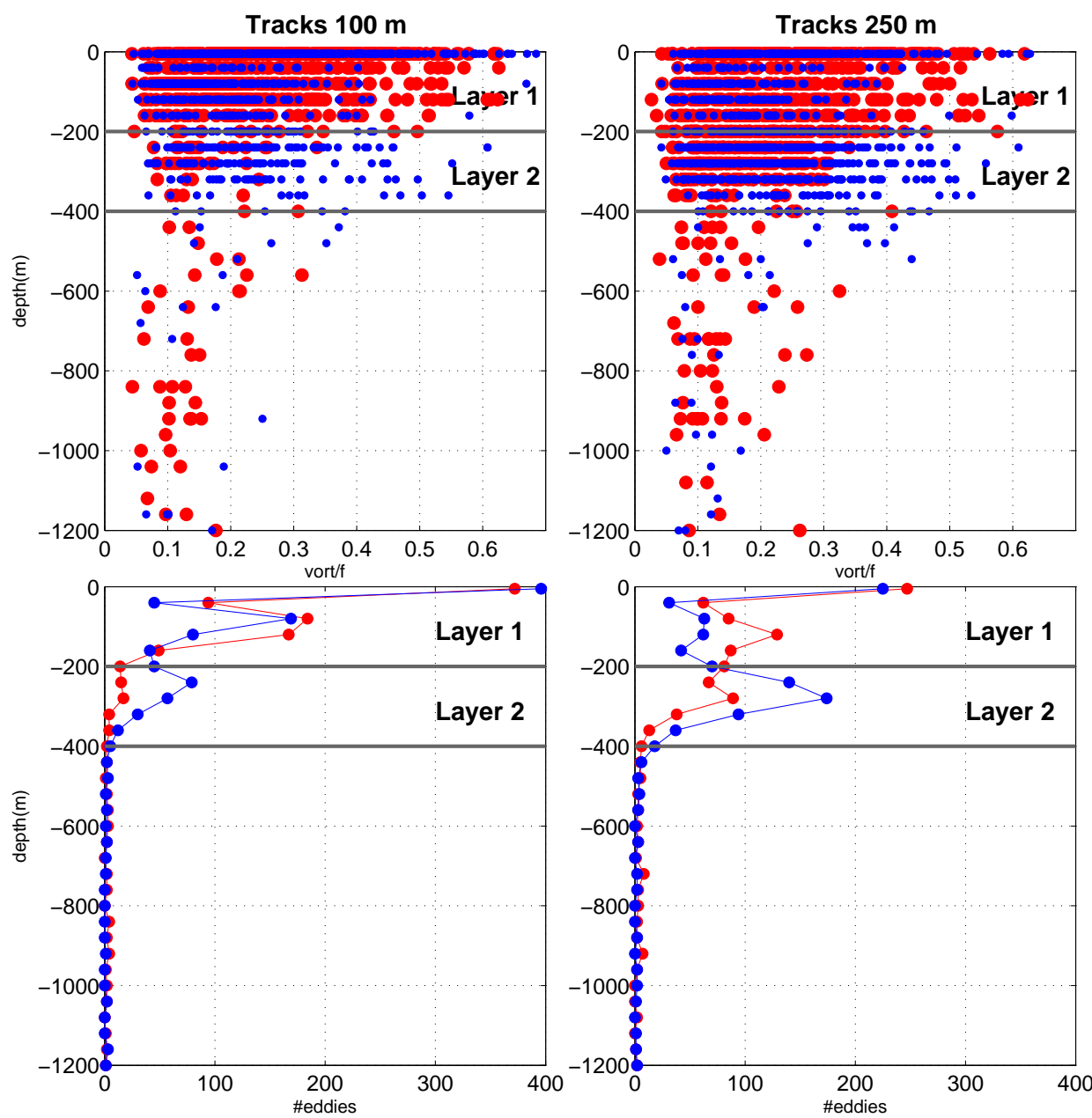

Figure 2: Distribution of eddies formed in the slope area (zoom on Fig. 1), from October to March. Top: diagram with all the detected eddies, as a function of their relative vorticity maximum and its depth. Bottom: number of eddies with maximum relative vorticity at each depth. On the left column, eddies detected at $100 \mathrm{~m}$ depth; on the right column, eddies detected at $250 \mathrm{~m}$ depth. Anticyclones are represented in red and cyclones in blue. Layers 1 and 2 are described in the text and have eddies with different characteristics. 
by the tracking algorithm. In the next two dates there is also a coincidence between the satellite SST images and the model outputs, and various of the features observed in the mesoscale field correspond to places where Swoddies are detected in the model.

Figure 4 shows two events for the winter of 1996 and one from the winter of 1997. Again, the model seems to be reproducing the same kind of observed structures. On February 17 1996, the current became unstable and various eddies are detected in the model, and the SST model anomalies are comparable in scales and positions to those observed in the satellite image. On March 24, 1997, some structures are visible on both satellite and model SST fields, and some of them are associated with the presence of Swoddies detected in the model outputs.

On March 14, 1998 (top Fig. 5), the satellite SST shows the presence of warm waters offshore at places where Swoddies were identified in the model. On December 14, 2006, the model SST shows a meandering IPC. Some days later (January 3, 2007) the current is again well developed and confined to the shelf and slope.

Unfortunatelly, the in-situ observations of these eddies are rare, and altimetry is not yet able to detect the scales of these structures at their formation sites which prevents a more robust statistical comparison with observations. However, the agreement in the spatial scales of the mesoscale field and synchronism with reality are encourageous, and support the use of this model simulation to study the winter eddies in this region.

\section{Statistics of Detected Eddies}

\subsection{Different Eddies in Depth and the Statistics of Vorticity}

As referred to above, there are distinct layers in the vertical, with different characteristics in terms of distribution of cyclones and anticyclones. For the eddy tracking done at $100 \mathrm{~m}$ depth (Fig. 2 - left) two main layers are distinguishable: a surface layer, from the surface down to around $200 \mathrm{~m}$ depth (Layer 1), which has stronger anticyclones (see the higher values of vorticity for anticyclones in layer 1 on Fig. 2 (top left)); and another layer, between 200 and $400 \mathrm{~m}$ depth (Layer 2), with more (Fig. 2 (bottom left)) and stronger (Fig. 2 (top left)) cyclones. Below $400 \mathrm{~m}$ depth, the number of detected eddies decreases (Fig. 2 (bottom left)). Even though, the cyclonic dominance seems to extend to around $600 \mathrm{~m}$ depth, and from 600 to $1000 \mathrm{~m}$ an anticyclonic dominance is observed, with more and stronger anticyclones than cyclones (this is more clear from 750 to $1000 \mathrm{~m}$ depth - Fig. 2 (top left)). 

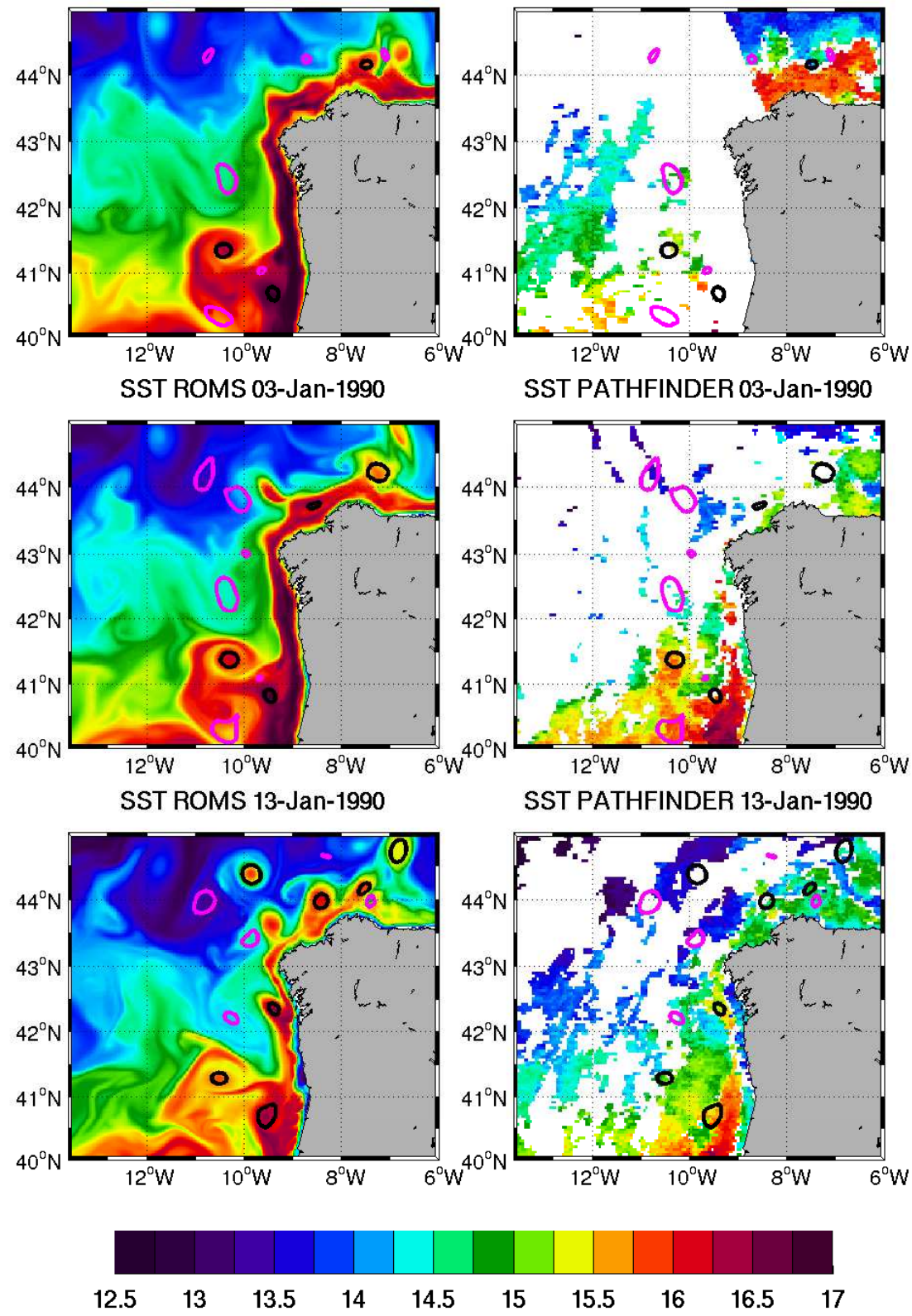

Figure 3: Comparison between model and satellite SST $\left({ }^{\circ} \mathrm{C}\right)$ for various days from the winter 1989/1990. The contours of the eddies identified with the eddy tracking at $100 \mathrm{~m}$ depth and intensified in the top $200 \mathrm{~m}$ of the water column are superimposed on both model and satellite SST fields. Anticyclones are in black and cyclones in magenta. 


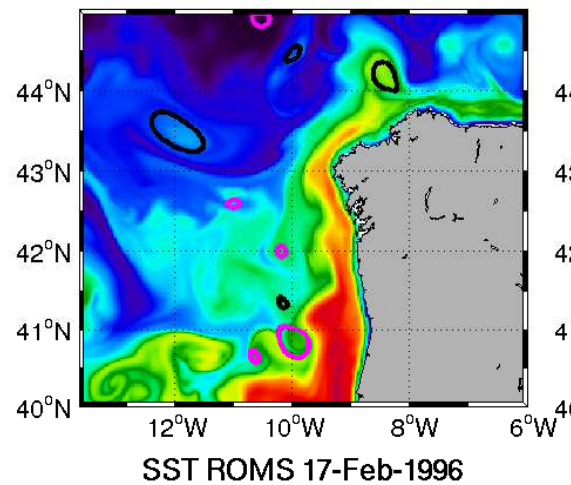

SST PATHFINDER 28-Jan-1996 

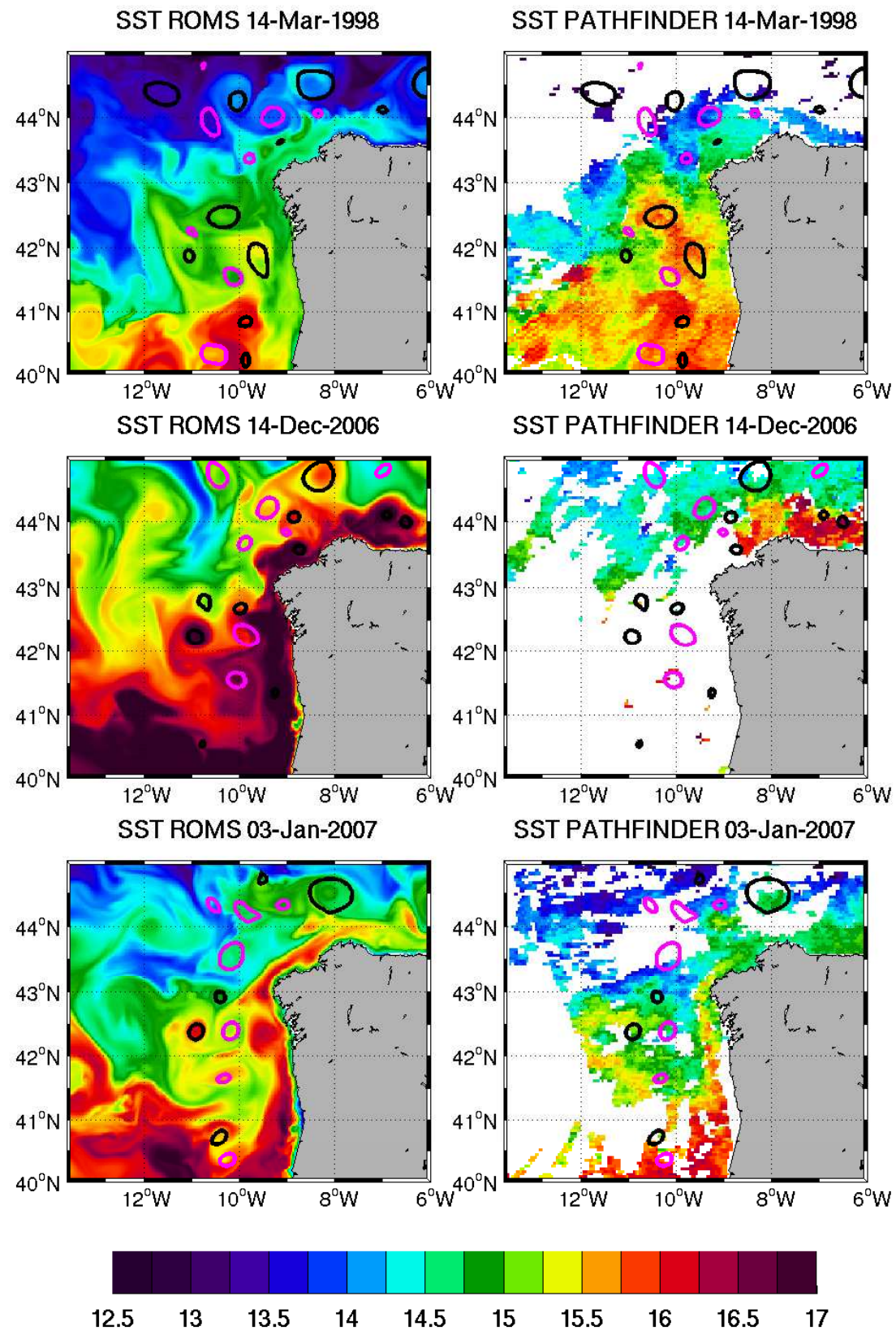

Figure 5: Comparison between model and satellite SST $\left({ }^{\circ} \mathrm{C}\right)$ for various days, from 1998 and from the winter 2006/2007. The contours of the eddies identified with the eddy tracking at $100 \mathrm{~m}$ depth and intensified in the top $200 \mathrm{~m}$ of the water column are superimposed on both model and satellite SST fields. Anticyclones are in black and cyclones in magenta. 
For the tracking done at $250 \mathrm{~m}$ (Fig. 2 - right) the results are similar. The main differences are: the detection of more cyclones in the 200-400 m layer (Layer 2 - Fig. 2 (bottom right)); and the increase in the ratio between the number of anticyclones and cyclones in the top layer (Layer 1) (the absolute number of both eddies decreases). This difference in the polarity is because in the upper layer the anticyclones are stronger than cyclones, and so their signal extends to deeper levels.

We compare these results with the statistics of the relative vorticity. To get the vorticity distribution in the slope area, we compute the Probability Density Function (PDF) of the relative vorticity for all instants from October to March, all model grid points contained in the slope area (area represented in the zoom plot in Fig. 1), and at various levels in depth. We represent the PDFs for 100 and $250 \mathrm{~m}$ depth (Fig. 6-left). The tails of the PDF correspond to the stronger negative and positive values of vorticity, usually located at the centre of the eddies. The PDF tail for $100 \mathrm{~m}$ depth (blue line) shows a clear tendency for negative values (anticyclonic), for values less than around -0.2 , although the largest absolute values are positive (cyclonic). At $250 \mathrm{~m}$ depth there is a clear tendency for positive (cyclonic) vorticities. In order to get a picture of the variation of the asymmetries in the water column, we computed the vorticity skewness at various depths, and represent the vertical profile on Fig. 6-right. The skewness measures the asymmetry of the probability distribution. In the top $200 \mathrm{~m}$ depth the dominance is anticyclonic (negative skewness). From 200 to $600 \mathrm{~m}$ depth it becomes cyclonic (positive skewness). Below this depth, from 600 till around $1100 \mathrm{~m}$, it is again anticyclonic (negative skewness). This is in agreement with the distribution of eddies per layers described in the previous paragraph, and it seems to be related with the vertical structure of the slope currents described in Teles-Machado et al. (2015b). The Iberian Poleward current is intensified in the upper $200 \mathrm{~m}$ of the water column, coincident with the anticyclonic dominance. Below, a counterflow denominated by Underslope Countercurrent (USCC), flows southward, centered at $400 \mathrm{~m}$ depth, and extending from 200-300 $\mathrm{m}$ to $600 \mathrm{~m}$ (depending on the month), and is coincident with the layer of cyclonic dominance. Finally, below $600 \mathrm{~m}$ depth, a poleward flow at the Mediterranean Water depths, the Iberian Poleward Slope Undercurrent (IPSU) is coincident with the levels of anticyclonic dominance.

To describe the statistics of their properties, the detected eddies were divided into 4 different groups: cyclones and anticyclones identified at $100 \mathrm{~m}$ depth, which have their relative vorticity maximum between the surface and $200 \mathrm{~m}$ depth (Layer 1 - Fig. 2); and cyclones and anticyclones identified at 

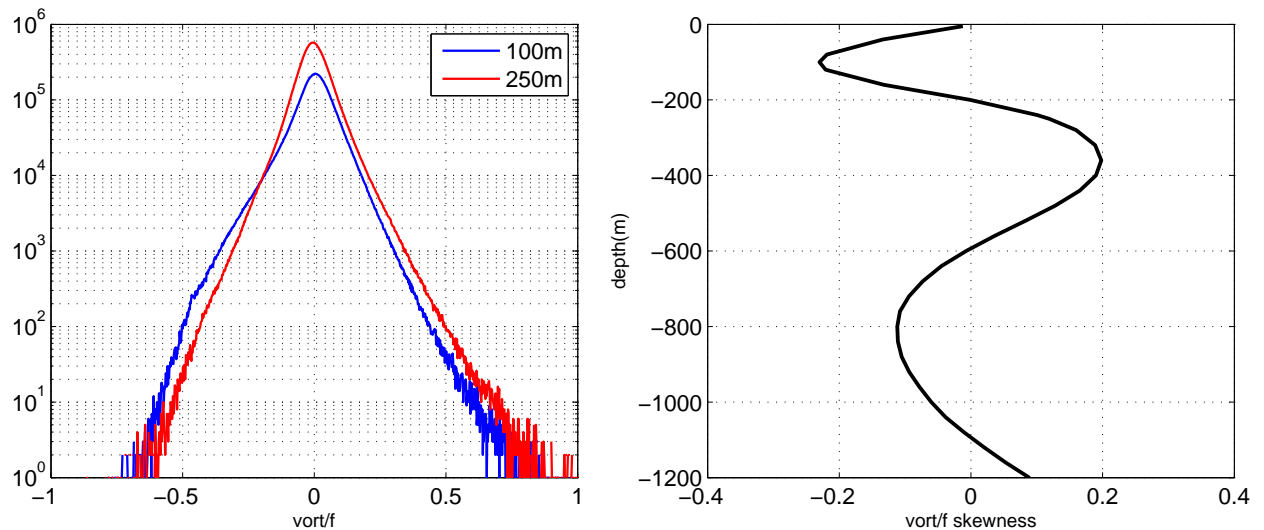

Figure 6: left: Probability density function (PDF) of vorticity fields in the slope area (zoom on Fig. 1) for 100 and $250 \mathrm{~m}$ depth. right: Skewness computed in the same domain, in function of depth.

$250 \mathrm{~m}$ depth, that have their relative vorticity maximum between 200 and $400 \mathrm{~m}$ depth (Layer 2 - Fig. 2). In the next section, we describe their characteristics.

\subsection{Characteristics of Surface and Mid-Water Eddies}

Figure 7 shows the seasonal cycle of the number of eddies formed on the slope separated by polarity, and layer of maximum intensity. The results show that eddies form every month. The seasonality is larger in the surface layer (Layer 1 - Fig. 2), with a larger number of anticyclones forming in November and from January to April, and a larger number of cyclones forming from January to June and in August. The larger number of cyclones obtained in August is probably related to coastal upwelling. In the deeper layer (Layer 2 - Fig. 2), the amplitude of the seasonal cycle is smaller, but there seems to be 2 peaks of cyclones formation, in July and November. So, it seems that there is a seasonal cycle in the top layer, but not so obviously in the deeper layer, which is coincident with what happens with the alongshore flows over the slope and over the shelf. As showed in Teles-Machado et al. (2015b), over the shelf and over the slope, in the upper $200 \mathrm{~m}$ of the water column, the seasonal cycle is dominant and represents around 40 to $60 \%$ of the total variability, while at the depths of the second layer it ranges from 20 to $30 \%$. In the rest of this paper, we will only consider the eddies formed from October to March. 

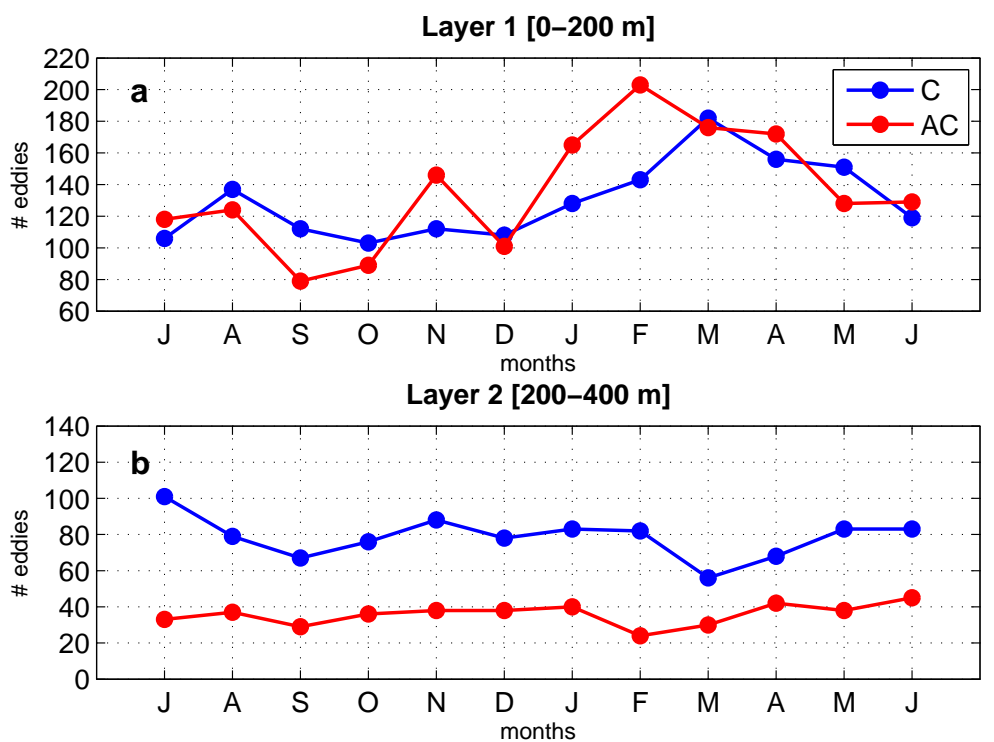

Figure 7: Total number of eddies formed on the slope area in each month (on the 20 years simulation). Top: cyclones (blue) and anticyclones (red) with maximum relative vorticity in the surface layer (Layer 1 - Fig. 2). Bottom: cyclones and anticyclones with maximum relative vorticity in the sub-surface layer (Layer 2 - Fig. 2). 

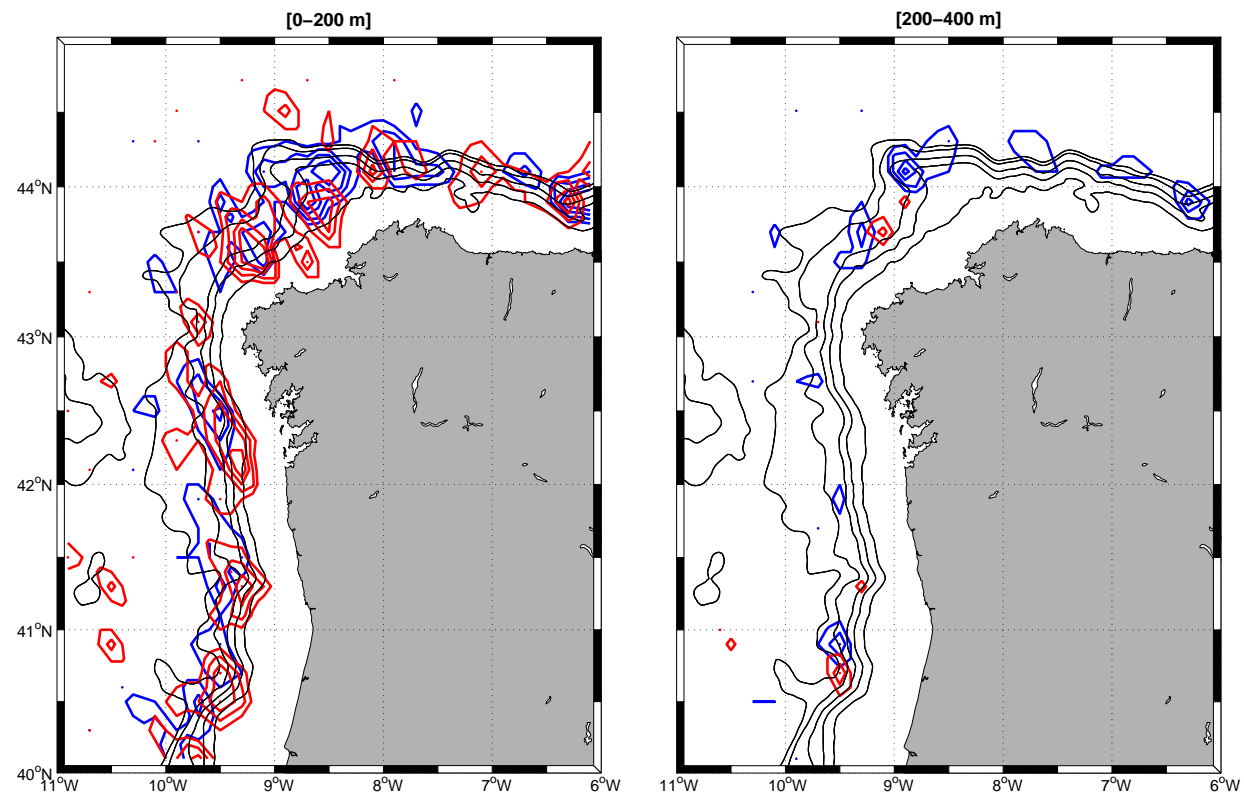

Figure 8: Maps with density of eddies formation. Left: cyclones (blue) and anticyclones (red) with maximum relative vorticity in the surface layer (Layer 1 - Fig. 2). Right: cyclones (blue) and anticyclones (red) with maximum relative vorticity in the sub-surface layer (Layer 2 - Fig. 2). The fields were obtained by counting the number of eddies formed in areas of $0.2^{\circ}$ lon $\times 0.2^{\circ}$ lat, which corresponds to an average of $368 \mathrm{~km}^{2}$, and we show the contours of 4 to 10 . The black contours represent the isobaths of 200, 500, 1000, 2000 and $2700 \mathrm{~m}$.

Figure 8 shows the preferential places of formation for each type of eddies. The slope is a favored location for the formation of eddies (i.e., higher density values over the slope in the 2 maps). Cyclones and anticyclones formation spots do not seem to overlap; the places with higher rate of cyclones formation seem to coincide with topographic contours veering cyclonically in the poleward direction, while anticyclones tend to form in places where topographic contours veer anticyclonically. This dependence in the topographic contours suggests that topography is important in the mechanisms of eddy formation. However, the number of eddies and the frequency of our model outputs are not enough to allow a detailed study about eddy formation. In the surface layer (Layer 1), there are more anticyclones formed, while in the Layer 2 there are more cyclones. 
Keeping only the eddies that formed on the slope (zoom area in Fig. 1) and from October to March, the number of identified eddies for the entire model simulation is: 880 anticyclones and 776 cyclones with maximum relative vorticity at the top $200 \mathrm{~m}$ (Layer 1), and 206 anticyclones and 463 cyclones with maximum relative vorticity between 200 and $400 \mathrm{~m}$ depth (Layer 2) (see table 1).

\begin{tabular}{|l|l|l|l|l|}
\cline { 2 - 5 } \multicolumn{1}{c|}{} & ACs & Cs & ACs & Cs \\
\cline { 2 - 5 } \multicolumn{1}{c|}{} & $0-200 \mathrm{~m}$ & $0-200 \mathrm{~m}$ & $200-400 \mathrm{~m}$ & $200-400 \mathrm{~m}$ \\
\hline North of CF (N) & 484 & 465 & 99 & 279 \\
\hline South of CF (W) & 396 & 311 & 107 & 184 \\
\hline Total & 880 & 776 & 206 & 463 \\
\hline
\end{tabular}

Table 1: Number of Anticyclones and Cyclones formed in the Layer 1 (0$200 \mathrm{~m}$ ) and Layer $2(200-400 \mathrm{~m})$, and formed north (north coast - N) and south (west coast - W) of Cape Finisterre (CF - Fig. 1).

To analyze the average vertical structure of each type of eddies, we subdivided the eddies in the ones formed north and south of Cape Finisterre $\left(43^{\circ} \mathrm{N}\right.$ - Fig. 1), because their characteristics are expected to be different due to their different thermohaline properties and to the different coastline orientation. Table 1 shows how many eddies of each type were formed on the slope, from October to March. We obtained the central profile of salinity, temperature, and relative vorticity for each eddy, and averaged over the entire population in consideration. The results are displayed in Fig. 9. There are more surface (Layer 1) anticyclones and they have on average higher values of relative vorticity (see Table 1 and Fig. 9 top-right). Anticyclones average maximum relative vorticity $(\xi / f)$ is approximately $-0.2(-0.27)$ for eddies formed to the south (north) of Cape Finisterre. Cyclones average maximum relative vorticity $(\xi / f)$ is approximately $0.15(0.225)$ for eddies formed to the south (north) of Cape Finisterre. Regarding the eddies with maximum relative vorticity between 200 and $400 \mathrm{~m}$ depth (Layer 2) the situation is the opposite. There are more cyclones than anticyclones and the cyclones are stronger than the anticyclones; their average maximum relative vorticity $(\xi / f)$ is approximately $0.2(0.24)$ for eddies formed to the south (north) of Cape Finisterre, with the maximum at an average depth of 250-300 m (Fig. 9 bottom-right). Anticyclones average maximum relative vorticity $(\xi / f)$ is approximately $-0.15(-0.16)$ for eddies formed to the south (north) of Cape Finisterre. The anticyclones formed to the south of Cape Finisterre have a salinity minimum at 300-400 $\mathrm{m}$ depth, that could be 
associated to the minimum of the salinity at the base of the central waters.

The Layer 1 anticyclones have stronger anomalies of temperature and salinity near the surface than the cyclones, suggesting that they keep in their core the warmer and saltier waters of the IPC. They have higher salinity values in the top $100 \mathrm{~m}$ of the water column, both north and south of $43^{\circ} \mathrm{N}$ (Fig. 9 (top-left)). Salinity and temperature values at the surface are higher on the western coast $\left(35.85 \mathrm{psu}\right.$ and $\left.16^{\circ} \mathrm{C}\right)$ than on the northern coast $\left(35.7 \mathrm{psu}\right.$ and $\left.14^{\circ} \mathrm{C}\right)$. Nevertheless, the surface anticyclones are on average stronger on the northern coast, with average $\xi / f$ reaching almost 0.3 , comparing to 0.2 on the west coast.

On Fig. 10 we show the trajectories of the eddies that are tracked continuously for at least 2 months, separated by layers and polarity. North of $41^{\circ} \mathrm{N}$, the trajectories are longer and extend further offshore. Some eddies on the Layer 1 (Fig. 10 - left) are tracked from the slope to the western boundary of the model domain. There are also some long trajectories near the northern boundary, and eddies that leave the smaller domain and enter again through the northern boundary. Generally the eddies move westward. Excluding the eddies in the northern coast, where the meridional propagation is constrained, the longest trajectories of the eddies formed on the western coast show anticyclones propagating preferentially southwestward and cyclones propagating preferentially northwestward, according to eddy propagation theory (McWilliams and Flierl, 1979) and to global eddy observations (Chelton et al., 2011).

The IPC is stronger in the upper $200 \mathrm{~m}$ of the water column, so it is expected that eddies formed through its destabilization also have their maximum velocity, or relative vorticity, at these levels. Moreover, as a poleward eastern boundary current, the IPC meanders are expected to be mainly anticyclones (rather than cyclones). The results presented in this section show that the average profiles of temperature and salinity of the Layer 1 anticyclones show higher anomalies of salinity and temperature near the surface, when comparing to cyclones. This suggests that these anticyclones contain IPC saltier and warmer waters in their core.

\section{The Strong IPC Winter of 1989/1990}

To illustrate some of the processes involved in Swoddies formation and detachment from the coast, we plotted various fields during the winter 1989/1990 (Fig. 11 and 12). This year is known for its strong IPC event (Garcia-Soto et al., 2002; Teles-Machado et al., 2015a) and various Swoddies 


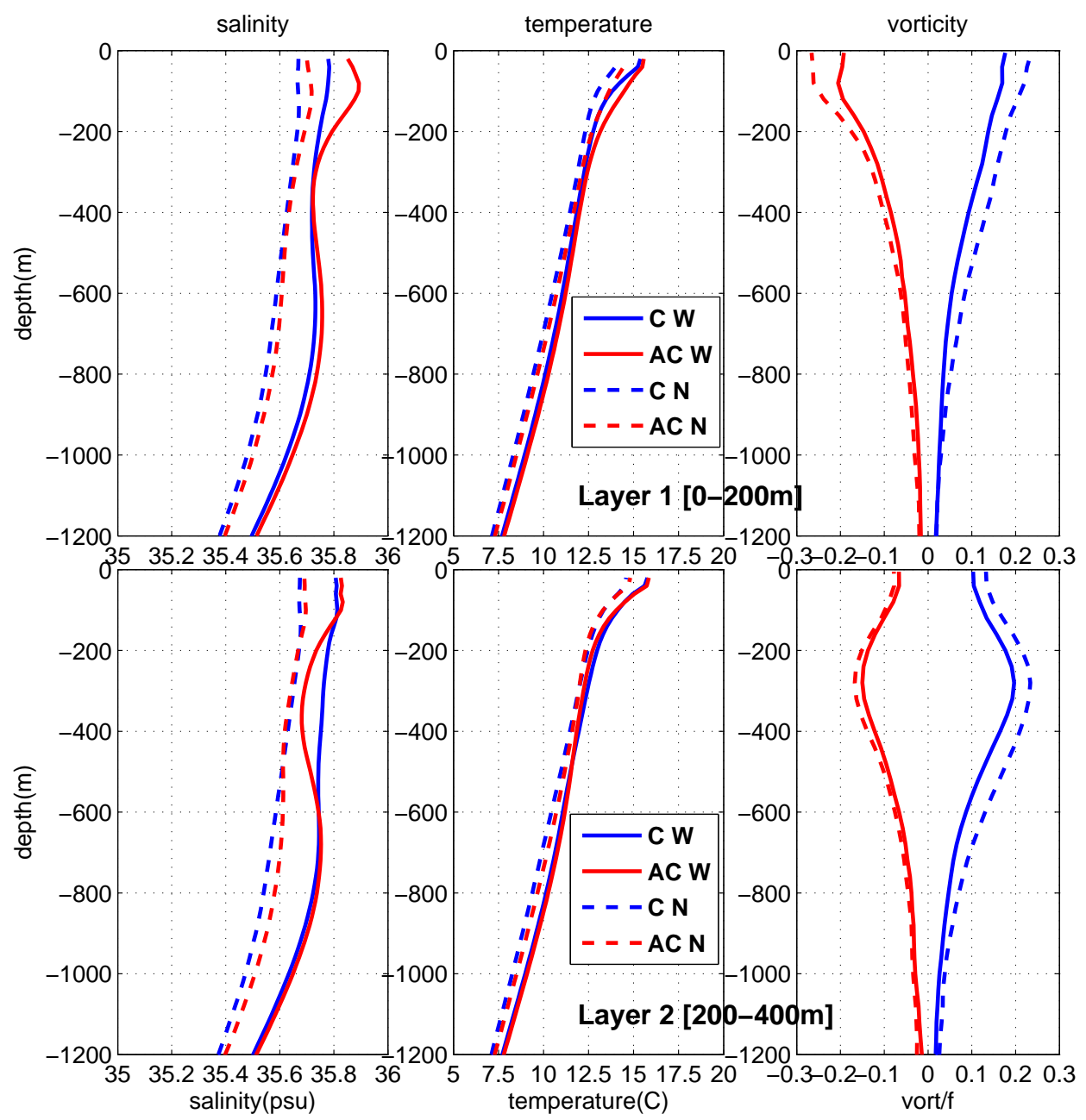

Figure 9: Average vertical profiles of salinity (left column), temperature (middle column) and vorticity (right column), of different eddies populations. On the top, eddies with maximum relative vorticity on the Layer 1 (0-200 $\mathrm{m} \mathrm{depth).} \mathrm{On} \mathrm{the} \mathrm{bottom,} \mathrm{eddies} \mathrm{with} \mathrm{maximum} \mathrm{relative} \mathrm{vorticity} \mathrm{on}$ the Layer 2 (200-400 $\mathrm{m}$ depth). The profiles in a continuous line represent another subdivision, of the eddies that formed on the slope area, but south of Cape Finisterre (Fig. 1), and the dashed-line eddies that formed on the slope area, but north of Cape Finisterre. 


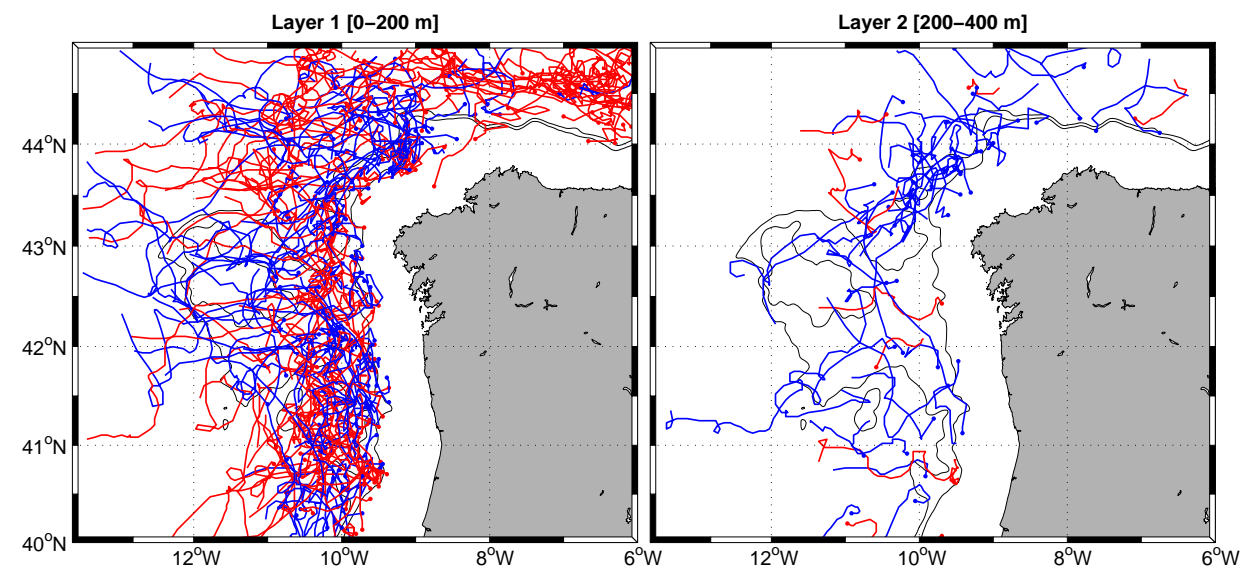

Figure 10: Trajectories of eddies tracked for a minimum of 2 months. Left: cyclones (blue) and anticyclones (red) with maximum relative vorticity in the surface layer (Layer 1 - Fig. 2). Right: cyclones and anticyclones with maximum relative vorticity in the sub-surface layer (Layer 2 - Fig. 2).

were observed on the northern coast, both by satellite SST and by in-situ measurements (Pingree and Le Cann, 1992b,a). On December 19, the IPC is intense and continuous north of $41^{\circ} \mathrm{N}$ (Fig. $11 \mathrm{~d}$ ), reaching speeds exceeding $0.4 \mathrm{~ms}^{-1}$. The current has a strong signal in the SST (Fig. $11 \mathrm{a}$ ), and it has negative (positive) vorticity on the inshore (offshore) flank of the current (Fig. $11 \mathrm{~g}$ ). This occurred under an event of strong southwesterly winds (see the time series of wind and wind stress on Fig. 13). Southerly winds were persistent in December 1989, but became particularly intense after December 10 (Fig. 13 a,b). After December 10, the southwesterly winds intensify and reach maximum intensity around December 16. After December 20, the winds slowed down. The intensity of the wind stress is significantly lower by December 29 (Fig. 13 a,b). The structure of the current on December 29 (Fig. $11 \mathrm{~b}, \mathrm{e}$ ) suggests the beginning of destabilization, although almost no new eddies were formed. On the northern coast, the flow separated from the slope downstream of Cape Ortegal (Fig. 11 e), leaving a signature on the SST field (Fig. $11 \mathrm{~b}$ ). On January 18, the instabilities grew even more, and 5 anticyclones identified by the eddy detection algorithm (Swoddies) are shedding from the slope (Fig. $11 \mathrm{c}, \mathrm{f}, \mathrm{i}$ ). These anticyclones carry IPC warmer and saltier waters offshore. A large eddy is developing on the northern coast, to the east of Cape Ortegal, in phase and at the same place as the eddy O90 described by Pingree and Le Cann (1992b) (also identified by 
its signal on the SST, see Fig. 3). The eddy tracking algorithm also identified various deep cyclones on the same day (thin blue lines). After January 18, southerly winds intensified again (see Fig. 13 a,b) and the current reestablishes (see February 7 fields on Fig. 12 a,d). O90 grew by absorbing smaller eddies that developed near Cape Ortegal (see evolution in Figures 11 and 12). After February 7, the wind intensity relaxed again (Fig. 13 a) and some additional Swoddies detached from the slope. Once again, there are deep cyclones near the detached anticyclones (Fig. 12 e). From February 17, to March 9, the two anticyclones positioned near $43^{\circ} \mathrm{N}$ merged into a bigger anticyclone visible on March 9 fields, centered at around $43.3^{\circ} \mathrm{N}$ and $10.8^{\circ} \mathrm{W}$ (Fig. 12 - March 9). This anticyclone propagates westward together with two companion cyclones, located southwestward and southeastward of the anticyclone, and centered at around $43^{\circ} \mathrm{N}$. By this time, the anticyclone O90 grew even bigger, by merging with smaller anticyclones generated near Cape Ortegal. The eddy detection algorithm underestimates the size of O90, where the detected radius is smaller than the effective radius of the eddy, probably because the eddy is located in the northern boundary of the smaller model domain.

\subsection{Time Evolution and Vertical Structure of Swoddies}

This section describes the evolution of the vertical structure of three eddies. Two of them are anticyclones intensified at the surface layer, and have been tracked for long periods: one was formed on the northern coast and the other on the western coast, and their trajectories are plotted in cyan in Fig. 1. The other is a cyclone intensified on the second layer, whose trajectory is plotted in yellow in Fig. 1.

The north coast anticyclone corresponds to the model O90, which formation is documented in Fig. 11 and 12. This eddy was first identified by the tracking algorithm on January 13, 1990, few days after a perturbation started developing east of Cape Ortegal, and was followed till January 8, 1991, when it left the smaller domain through the northern boundary. Figure 14 shows the vertical structure of the thermohaline properties of the eddy for 5 different instants in time, indicated in the trajectory plot (Fig. 1). Figure 15 shows the vertical structure of the normalized relative vorticity and meridional velocity for 3 different instants. On January 13 (Fig. 14, January 13), when the eddy is first detected, its diameter is around $60 \mathrm{~km}$, the azimuthal velocity is maximum at the surface and reaches $0.5 \mathrm{~m} \mathrm{~s}^{-1}$ (Fig. 15). The temperature and salinity values at its core are around $15^{\circ} \mathrm{C}$ and 35.75 psu, respectively. Two months later, on March 4 (Fig. 14, March 


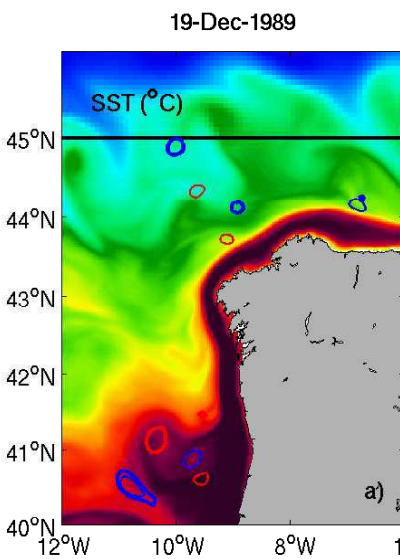

29-Dec-1989

18-Jan-1990
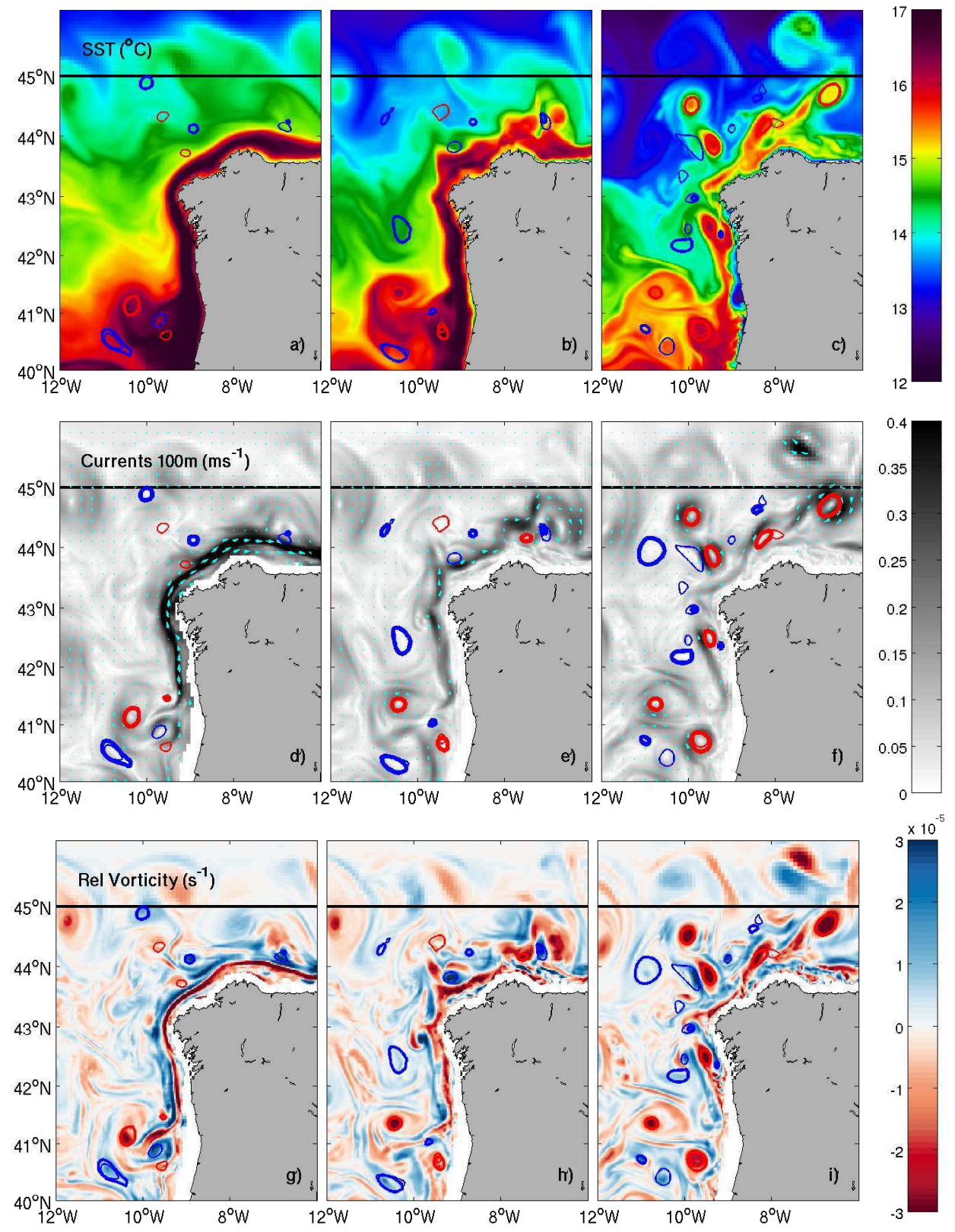

Figure 11: Swoddies in the winter of 1989/1990. The columns represent different days. First row: SST; Second row: currents vector field and speed at $100 \mathrm{~m}$ depth; Third row: relative vorticity at $100 \mathrm{~m}$ depth. Surface (intensified in Layer 1 - Fig. 2) anticyclones and cyclones, are identified, respectively, with thick red and blue lines. Anticyclones and cyclones intensified at the subsurface (Layer 2 - FR2 2) are represented with a thin line, and also in red and blue. The black line separates the domains A0 and A1, and the eddies were tracked in the grid A1. 

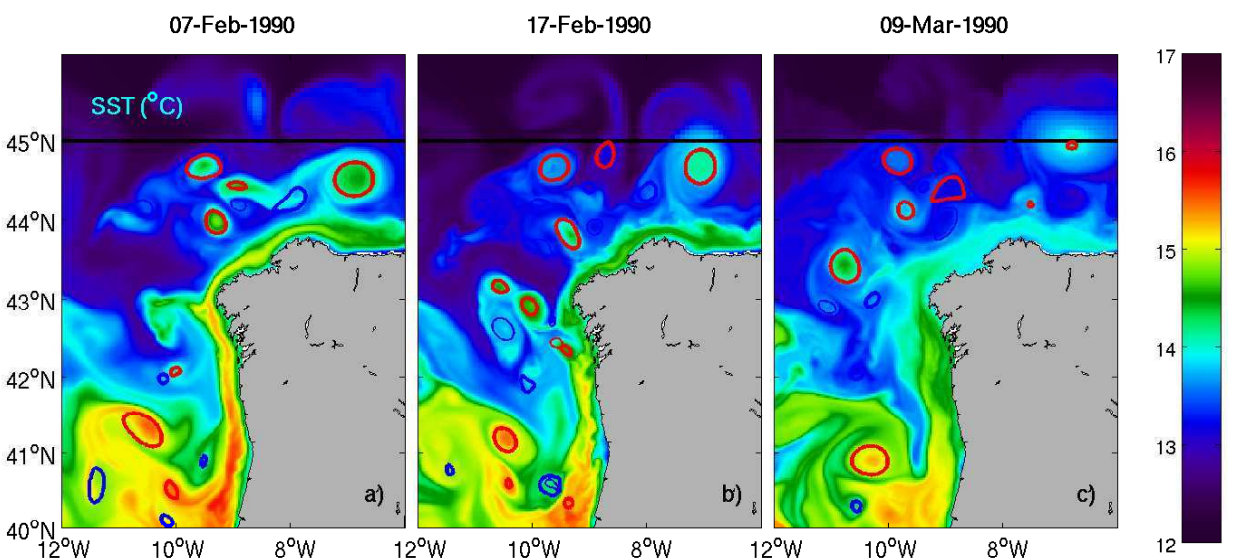

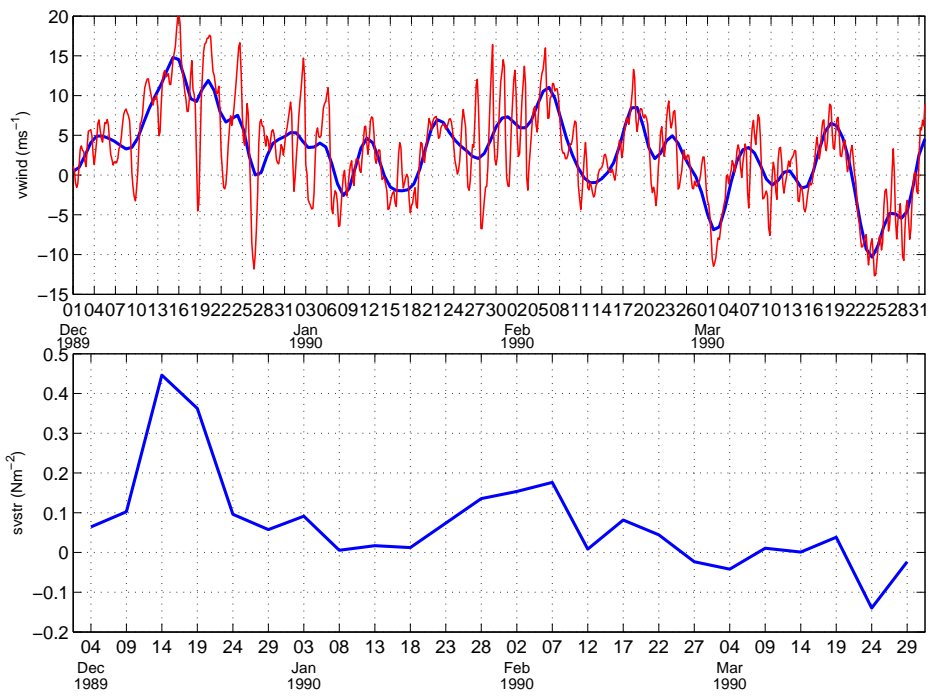

Figure 13: Evolution in time of the area averaged wind (averaged in domain W - Fig. 1), to follow the event described in Fig. 11 and 12. a) meridional component of the wind (red) and filtered the scales below 5 days (blue); b) 5 days average meridional wind stress from model outputs and coincident with model fields. 
4), the eddy increased in size, because it merged with smaller anticyclones that also formed near Cape Ortegal (Fig. 11 and 12), and has a diameter of approximately $100 \mathrm{~km}$. The temperature and salinity at the core decreased. By this time the mixed layer reached deeper, homogenizing the eddy core (Fig. 14, March 4). The mixing is deeper inside the eddy than outside, due to its high salinity values which induce critical static stability soon after cooling. After March, the surface re-stratifies with the summer warming, and by July and August the eddy core is isolated from the surface, hidden by the warmer and saltier surface waters (Fig. 14, July 7, and August 11). The salinity reached higher values at the eddy location. By this time the relative vorticity and the azimuthal velocity have decreased (Fig. 15, O90, July 7). On December 24, 1990, almost one year after the formation, the mixed layer reached deeper levels again, homogenizing the eddy core again, from the surface to around $200 \mathrm{~m}$ depth (Fig. 14, December 24). The Swoddy has slowed down, but not significantly, since its azimuthal velocity, one year after being born, still reaches $0.45 \mathrm{~m} \mathrm{~s}^{-1}$ (Fig. 15, O90, December 24). Fifteen days later, by January 8, 1991, this Swoddy left the smaller model domain through the northern boundary (Fig. 1). Although this eddy formed in the same place and time as the observed O90, the trajectories are completely different, and the real O90 propagated westwards much faster: it was tracked till August 1990, when it was located near $12^{\circ} \mathrm{W}$, while the modeled $\mathrm{O} 90$ was still near $7.5^{\circ} \mathrm{W}$ on the same month.

Just for comparison, we also plot the evolution of the vertical structure of an anticyclone intensified at the surface, but formed on the west coast. Because there was no long track for the winter of 1989/1990, we describe an eddy from the winter of $2001 / 2002$. This eddy was tracked from January 8,2002 , to July 12,2003 . It was generated on the slope, at around $40.7^{\circ} \mathrm{N}$ and propagated south-eastward, leaving the domain through the western boundary, at the latitude of $39.6^{\circ} \mathrm{N}$, one year and a half later (Fig. 1). This eddy rotates slower than the northern one; it has lower values of relative vorticity and the azimuthal velocity reaches $0.2 \mathrm{~m} \mathrm{~s}^{-1}$ (Fig. 15). Its average relative vorticity $(\xi / f)$ in the first month is not maximum at the surface, but at $100 \mathrm{~m}$ depth, and its value is around -0.35 (Fig. 15 - W02). We show the evolution of its thermohaline structure in Fig. 16. The evolution is not much different from the northern Swoddy. On January 28, it is still close to the slope, and has a diameter of around $50 \mathrm{~km}$ (Fig. 16, January 28). On March 14, the diameter almost doubled, the mixed layer deepened, and the eddy core was well mixed. As for O90, vertical convection is stronger inside the eddy, than outside. By June 17, there is already a surface re-stratification (and by August 1), and the eddy core is hidden below the surface. On 


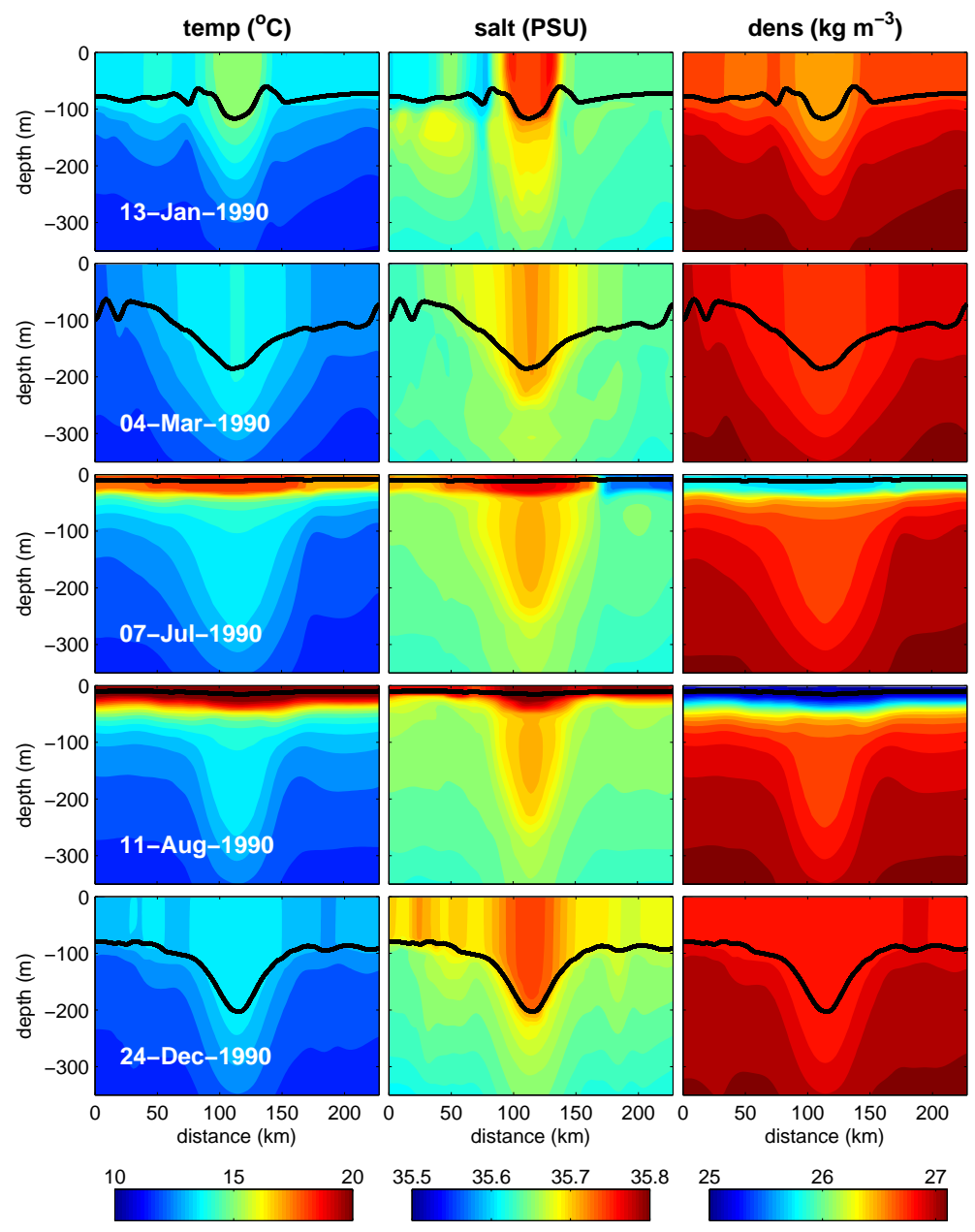

Figure 14: Zonal sections of temperature (left column), salinity (middle column) and density (right column), for different dates. The black line represents the mixed layer depth. The sections cross the center of the eddy. This Swoddy trajectory is represented in Fig. 1, the one that formed on the northern coast. Corresponds to the observed O90. 

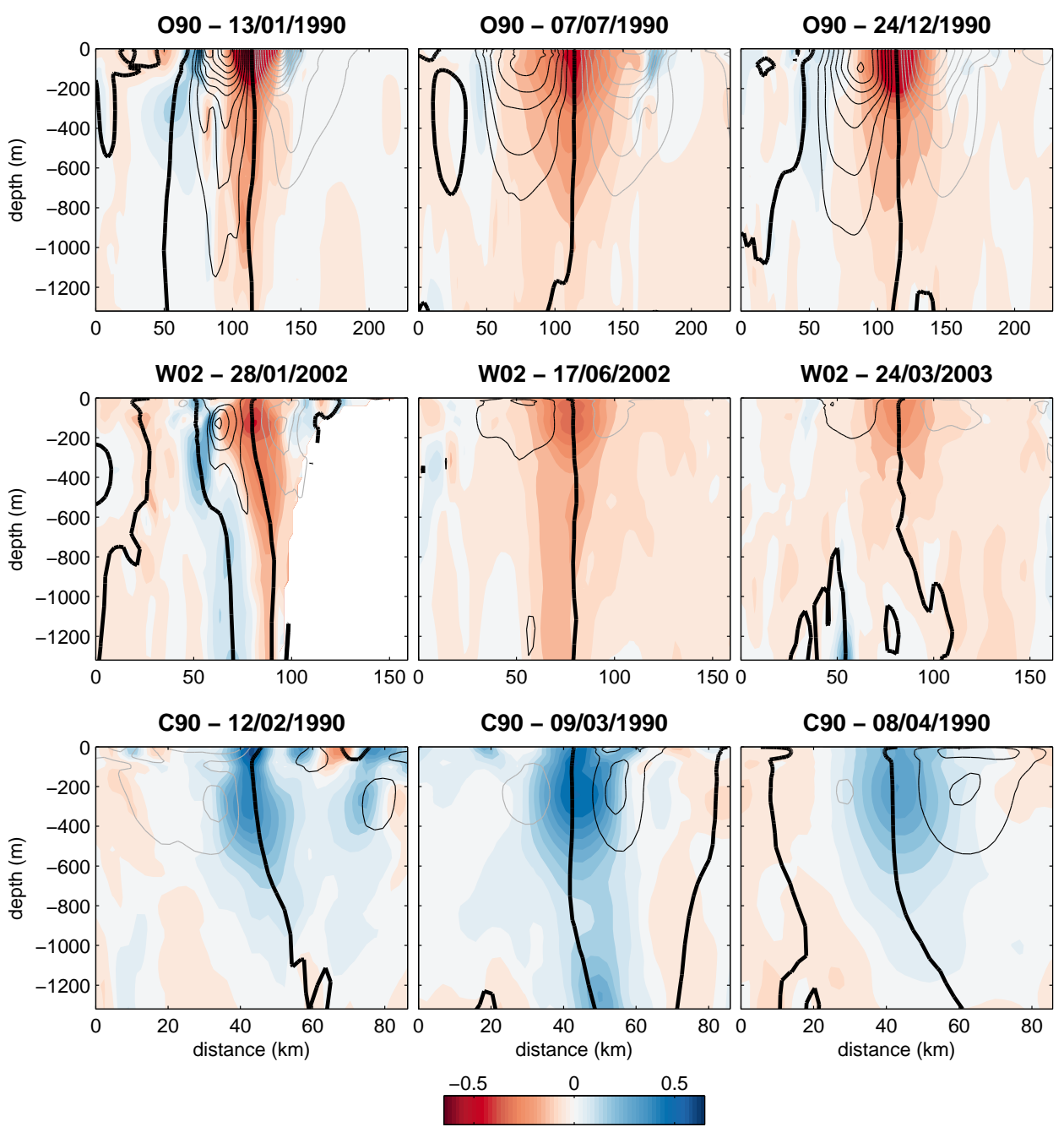

Figure 15: Zonal sections of normalized relative vorticity $\xi / f$ (colors) and meridional velocity (contours), for different dates. Top: eddy O90 (Fig. 14); Middle: eddy W02 (Fig. 16); Bottom: eddy C90 (Fig. 18). The velocity contours have an interval of $0.05 \mathrm{~m} \mathrm{~s}^{-1}$; the thick black contour represents null velocity, thin black contours are northward velocities, and thin grey contours are southward velocities. 
March 24, 2003, the Swoddy is slowing down its rotation, as visible in Fig. 15 relative vorticity (and meridional velocity). Four months later it leaves the smaller model domain through the western boundary. At the moment of formation, both Swoddies extend to deeper than $1300 \mathrm{~m}$ depth (Fig. 15). One year after, both Swoddies have slowed down, and became increasingly confined to shallower levels.

Figure 17 shows the vertical structure of the normalized vorticity of another surface intensified anticyclone and one of its companion subsurface cyclones, that were shown in Fig. 12 - March 9) (position of the vertical section is represented with a black line in Fig. $12 \mathrm{i}$ ). The structure of the anticyclone is similar to that of O90 and W02, with a diameter of around $40 \mathrm{~km}$. The companion cyclone has its maximum vorticity at around $250 \mathrm{~m}$ depth, a diameter of around $20 \mathrm{~km}$, and its main core is mostly confined to the top $800 \mathrm{~m}$ of the water column. We show the evolution of the vertical structure of the thermohaline properties of this cyclone in Fig. 18, and the vertical structure of the normalized relative vorticity and meridional velocity in Fig. 15. This eddy was tracked for a short period, it was first identified by the eddy tracking algorithm in February 12, 1990, and tracked till April 8 of the same year. The trajectory is shown in Fig. 1 (yellow line). Its average relative vorticity $(\xi / f)$ is maximum between 200 and $400 \mathrm{~m}$ depth, (Fig. 15 - bottom) and reaches a maximum in March 9, 1990. The azimuthal velocity reaches $0.1 \mathrm{~m} \mathrm{~s}^{-1}$. The core of the cyclone is more visible in the salinity sections (Fig. 18) because it is less affected by stratification. The cyclone has higher values of temperature and salinity than the surrounding waters. The SST is also higher at the eddy location (Fig. 18 - temperature in February 17 and March 9). When the surface layer begins to warm the eddy core becomes hidden by the warmer surface waters (Fig. 18 - temperature in April 8). It is not possible to see what happens to the cyclone in a seasonal cycle, because this one was tracked only for 2 months.

Figure 19 shows the average evolution of the maximum normalized relative vorticity of a population of surface intensified anticyclones and subsurface intensified cyclones, that were tracked for a minimum of 90 days. The plot shows that on average, both intensify in the first 20 days, and after this period both start to spin down, although the cyclone vorticity decreases faster than the anticyclone vorticity. By considering only the eddies that were tracked for a minimum of 90 days, we obtain 58 surface intensified anticyclones and 15 subsurface intensified cyclones. This difference in the number of eddies is expected, because the anticyclones identified in the top layer are in total around twice the number of cyclones identified in the subsurface layer (see Table 1), but the ratio for the tracks longer than 90 days 


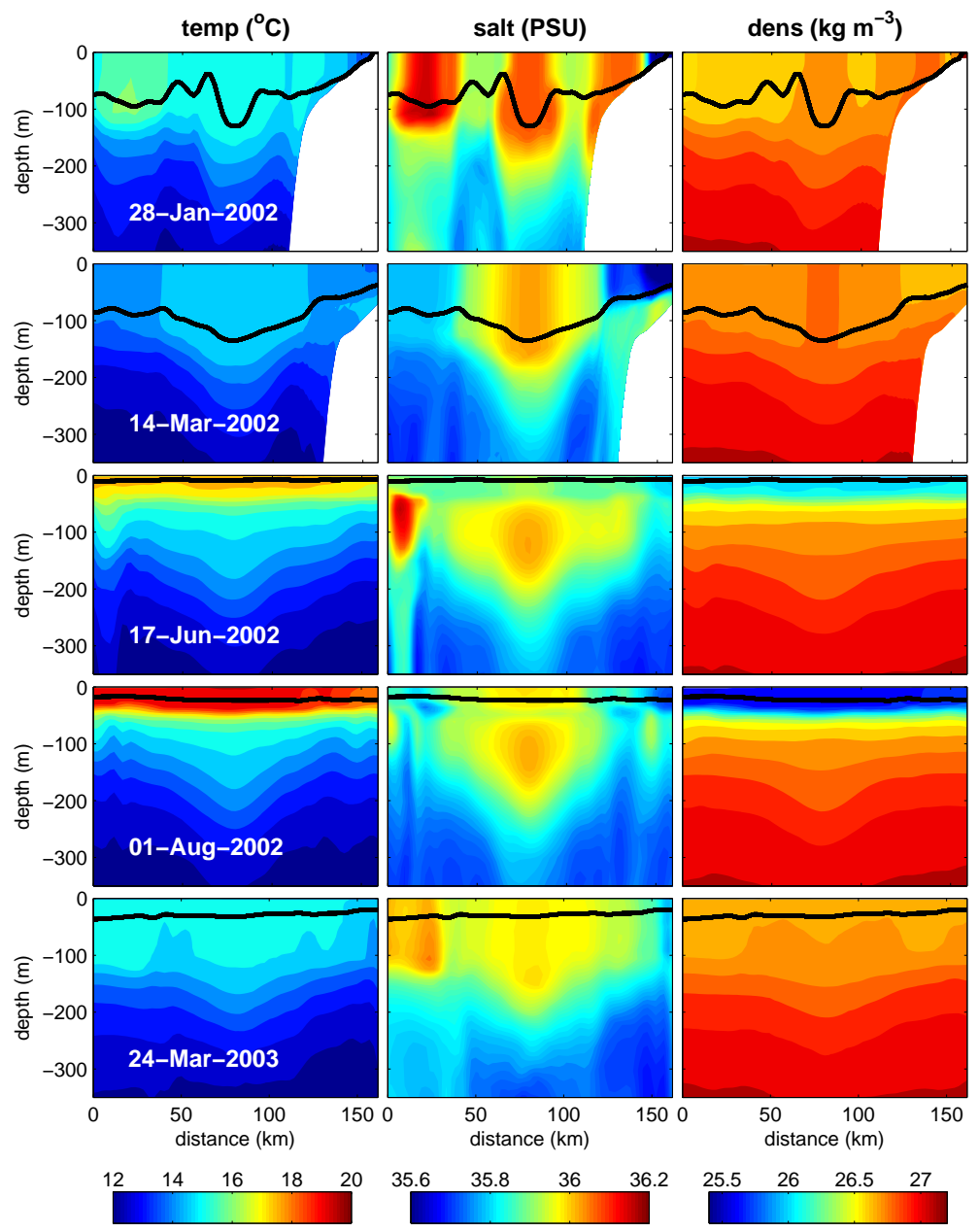

Figure 16: Zonal sections of temperature (left column), salinity (middle column) and density (right column), for different dates. The black line represents the mixed layer depth. The sections cross the center of the eddy. This Swoddy trajectory is represented in Fig. 1, the one that formed on the western coast. 


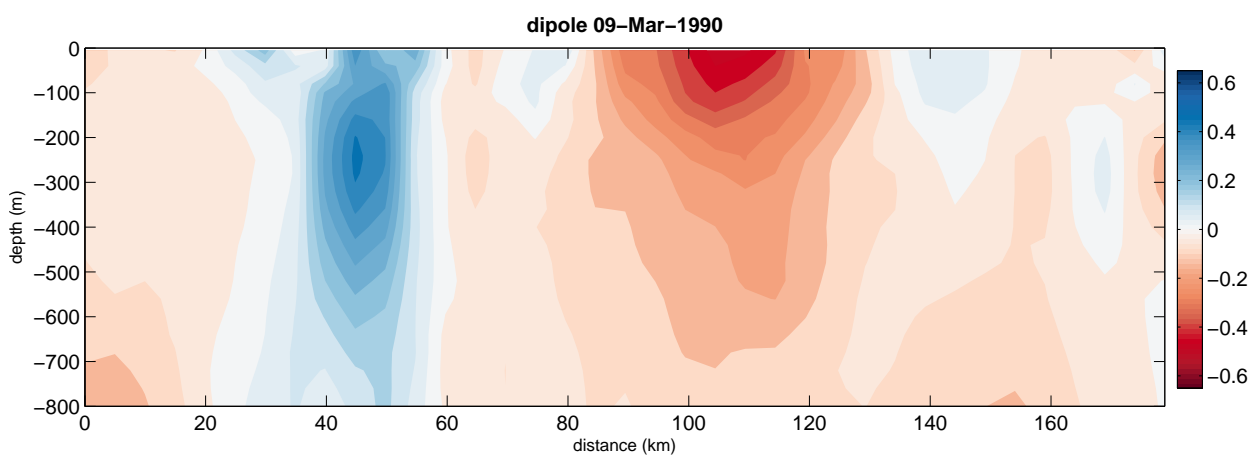

Figure 17: Vertical section of normalized relative vorticity $\xi / f$ crossing a Swoddy and a Deep Cyclone from the 09-March-1990 tripole (black line in Fig. 12 i).

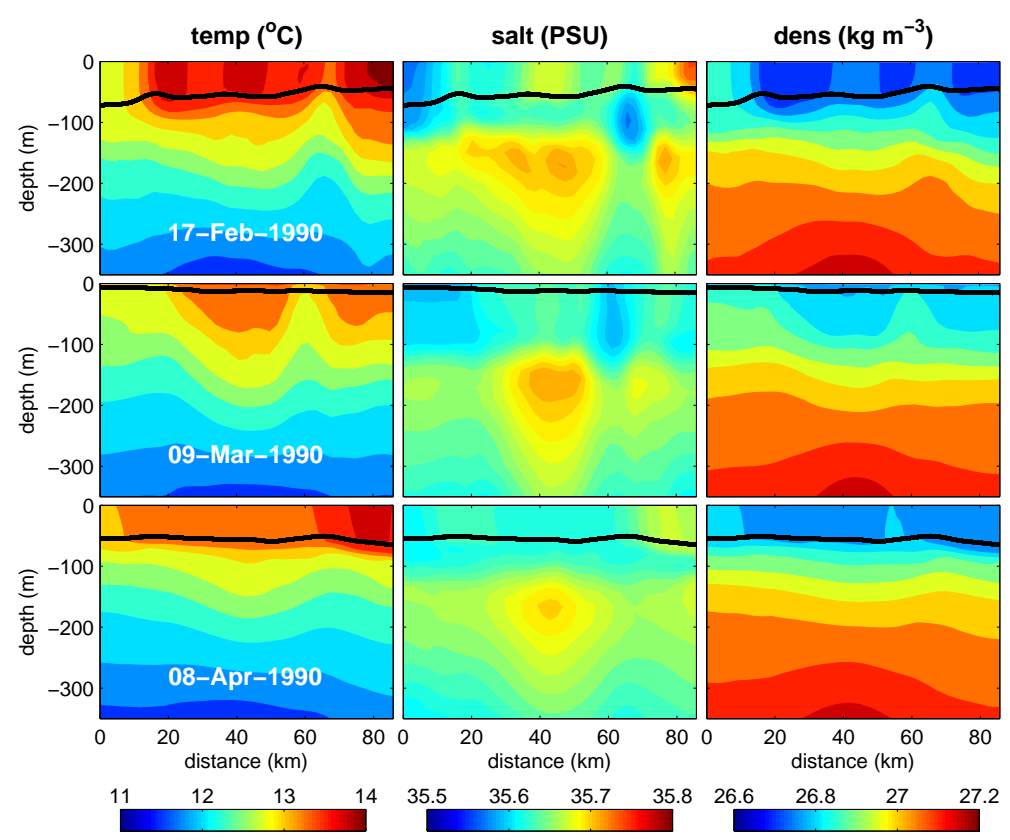

Figure 18: Zonal sections of temperature (left column), salinity (middle column) and density (right column), for different dates. The black line represents the mixed layer depth. The sections cross the center of the eddy. This cyclone trajectory is represented in Fig. 1 in a yellow line. 


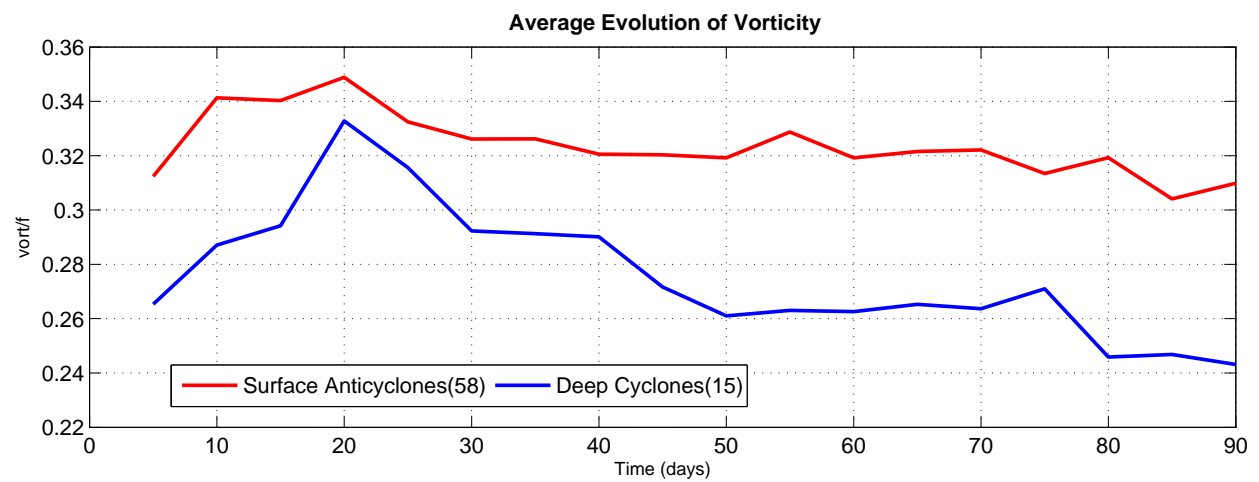

Figure 19: Average evolution in time of the maximum normalized relative vorticity of all of the surface intensified (Layer 1 (0-200 m depth)) anticyclones and subsurface intensified (Layer 2 (200-400 m depth)) cyclones that were tracked for a minimum of 90 days.

is larger, suggesting that the cyclones are tracked for shorter periods than the anticyclones.

\section{Discussion and Conclusions}

This study analyzes the eddy field in the Northwestern Iberian region with a particular focus on the eddies arising from the destabilization of the IPC. It is the first time that an analysis of the Swoddies is done in a 20-year high resolution ocean simulation. The eddies that contain the IPC waters are usually anticyclones formed in the slope and with maximum relative vorticity in the top $200 \mathrm{~m}$ of the water column. An eddy tracking algorithm (Nencioli et al., 2010) is used to identify and track the eddies that formed in the winter, in the slope, in our model simulation. Most of the information previously known about these eddies was obtained by analysis of satellite SST images that are frequently affected by cloud cover in the winter, or by in-situ observations of sporadic eddies. The model reproduces the formation of some of the Swoddies at the same time and place, and with similar sizes as observed in satellite SST.

We found there are distinct layers in the vertical, with different characteristics in terms of relative vorticity distribution. The top $200 \mathrm{~m}$ of the water column has an anticyclonic dominance, with stronger anticyclones; in the layer between 200 and $600 \mathrm{~m}$ depth the dominance is cyclonic, with more and stronger cyclones; and from 600 to $1000 \mathrm{~m}$ there is again an an- 
ticyclonic dominance, with more and stronger anticyclones than cyclones. These layers are coincident with the vertical structure of the slope currents. The Iberian Poleward current is intensified in the upper $200 \mathrm{~m}$ of the water column, coincident with the anticyclonic dominance. Below, a counterflow denominated by Underslope Countercurrent (USCC), flows southward, centered at $400 \mathrm{~m}$ depth, and extending from 200-300 $\mathrm{m}$ to $600 \mathrm{~m}$ (depending on the month), and is coincident with the layer of cyclonic dominance. Finally, below $600 \mathrm{~m}$ depth, a poleward flow at the Mediterranean Water depths, the Iberian Poleward Slope Undercurrent (IPSU) is coincident with the levels of anticyclonic dominance. The vertical structure of the currents in this model simulation is described in Teles-Machado et al. (2015b). The formation of anticyclones at Mediterranean Water depths (Meddies), by meandering and instability of the IPSU was already described in Bower et al. (1997). We also found that eddies form mainly near topographic features: cyclones form mainly where topographic contours veer offshore, in the poleward direction; anticyclones tend to form in places where topographic contours veer anticyclonically. This means anticyclones form mainly in the equatorward side of the canyons and in the poleward side of promontories or capes (Fig. 8). The main places for the anticyclones formation are in the southern sides of Aveiro and Porto Canyons, in front of Galician Rias $\left(42-43^{\circ} \mathrm{N}\right)$, northwestward of Cape Finisterre and eastward of Ortegal Promontory, or Cape Ortegal (see locations in Fig. 1). This is in agreement with the study of Peliz et al. (2003b) that show in idealized model configurations representing the IPC, that anticyclones form mainly downstream of topographic features, by separation of the poleward flow. Eddies generation from a coastal or slope current are usually result of barotropic, baroclinic, Kelvin-Helmoltz, or ageostrophic frontal instabilities. A general review on these processes is presented in Carton (2010). In this case, the influence of topography and the coincidence between the different cores of the slope currents and the distribution of eddies in the vertical, suggests that the eddies in the three layers form through a mechanism of separation of the slope currents, consistent with the mechanism proposed by D'Asaro (1988) for the formation of an anticyclone observed off Alaska. This mechanism was also mentioned by Bower et al. (1997) for the generation of Meddies. D'Asaro (1988) explains the influence of topography based on vorticity generation in the frictional boundary layer on the inshore side of the current. Our maps of the relative vorticity of the IPC at $100 \mathrm{~m}$ depth for the winter of 1989 (Fig. $11 \mathrm{~g}$ )) show higher values of anticyclonic vorticity on the inshore flank of the current, than of cyclonic vorticity on the offshore flank, which favours D'Asaro (1988) hypothesis. This also seems to happen in other regions, as for example in 
California, for the Cuddies formation (Garfield et al., 1999). Molemaker et al. (2015) study the process of Cuddies formation using model simulations and verified that the California Undercurrent separates from the slope in many downstream locations, satisfying the criterium of ageostrophic centrifugal instability, which gives rise to ageostrophic submesoscale currents, and reorganizes into anticyclonic, coherent mesoscale vortices. A detailed study on the instability processes is out of the scope of this paper, and requires higher resolution (both is space and time) controlled simulations. It is an interesting topic for future research.

We describe one event of strong IPC and of its destabilization and formation of a series of eddies in the winter of 1989/1990. In this event, we show that there is a relationship of Swoddy formation with the wind variability. There are two periods when various eddies are formed (14 to 29 of December 1989 and 7 to 12 of January 1990), both coincident with the relaxation of southerly winds. A sudden decrease in the wind, results in the development of instabilities in the IPC and formation of eddies. The IPC intensity (net meridional transport on domain W - Fig. 1), presents a large synoptic variability, mainly forced by the variability of the meridional component of the wind (the correlation between both 20-years time series is $61 \%)$.

The shedding of surface intensified anticyclones from the slope is described for two different occasions, and on both, it is accompanied by the shedding of subsurface intensified cyclones. The existence of these cyclones is described in Peliz et al. (2003b) that describes the destabilization of the IPC and formation of surface intensified anticyclones and subsurface intensified cyclones. In the same study it is also demonstrated the importance of these cyclones for the separation of the anticyclones from the slope and their propagation offshore. We verify that in our model a number of subsurface cyclones are also produced at the surface anticyclones shedding times, and we observe clear signs of interaction between both. One example is presented in Fig. 12 in March 1990, where two cyclones propagate westward together with a surface anticyclone. The vertical structure of one of these cyclones and the anticyclone is shown in Fig. 17. As these eddies interact, their trajectory is mostly a result of mutually induced movements, between close enough eddies, centered at the same vertical level or at different levels (McWilliams (2006), Chap. 2). As Peliz et al. (2003b) show, subsurface cyclones are important in pushing surface anticyclones offshore; and Carton et al. (2013) show in analytical and numerical studies that a deep Meddy can also interact with a surface anticyclone, and this interaction can explain the U-shape trajectory of the surface anticyclone F90, observed by Pingree and 
Le Cann (1992b). The mutually induced eddy movements, between eddies at the same or at different depths, are a chaotic system (McWilliams (2006), Chap. 2), and that is why the model cannot reproduce the trajectories of the Swoddies, although it is able to reproduce their instants and places of formation. For example, the real O90 was observed to propagate from $7^{\circ} \mathrm{W}$ to $12^{\circ} \mathrm{W}$ (Pingree and Le Cann, 1992b), while the one formed in the model only propagated to $7.5^{\circ} \mathrm{W}$ in the same amount of time.

In general the subsurface cyclones spin down faster than the surface anticyclones, that are generally tracked, and conserve their maximum relative vorticity, for longer periods. This dominance of the anticyclonic vorticity is characteristic of the subsurface anticyclonic coherent vortices, that are usually named by Submesoscale, Coherent Vortices, SCVs (McWilliams, 1985). We verify that anticyclones vertical structure at the moment of formation extends to deeper than $1200 \mathrm{~m}$, and this vertical extent decreases with time. It is verified that they can survive winter deep convection that homogenizes their core. Convection is deeper inside the eddy than outside, suggesting that the surface intensified anticyclones can have an important role in ventilating central waters.

Our study contributes to describe the characteristics of the Autumn/Winter mesoscale field in the Northwestern Iberia with particular focus on the anticyclonic Swoddies, that carry the IPC warm and salty waters offshore. It is not known if Swoddies can also form in the Summer, and if they do, how do they interact with the upwelling front and how do they relate with summer surface filaments. The effective role of the Swoddies in the cross-shore transport of heat and salt, and also of coastal enriched waters (as shown in Rossi et al. (2013) for one summer filament) are still to be quantified. It is also not known what is the impact of the Swoddies for the regional heat and salt balances. The details of the Swoddies formation near the capes, the effects of the submesoscale in the instability processes, as well as possible interactions between Swoddies and Meddies are also topics for future research.

\section{Acknowledgement}

This study had the support of the Portuguese Science Foundation (FCT) (MedEx (MARINERA/MAR/0002/2008), Sflux (PTDC/MAR/100677/2008), SHARE (RECI/GEO-MET/0380/2012), and UID/GEO/50019/2013-IDL), and of the Office of Naval Research (grant N00014-12-1-0939). ATM was funded by FCT through grants SFRH/BD/40142/2007 and SFRH/BPD/100720/2014. 
We also thank two anonymous reviewers for their constructive comments on the manuscript.

\section{References}

Aguiar, A., Peliz, A., Carton, X., 2013. A census of Meddies in a long-term high-resolution simulation. Progress in Oceanography 116, 80-94.

Bower, A., Armi, L., Ambar, I., 1997. Lagrangian Observations of Meddy Formation during A Mediterranean Undercurrent Seeding Experiment. Journal of Physical Oceanography 27, 2445-2575.

Carton, X., 2010. Oceanic vortices. In: Flor, J.-B. (Ed.), Fronts, Waves and Vortices in Geophysical Flows. Vol. 805. Springer Berlin Heidelberg, Berlin Heidelberg.

Carton, X., Le Cann, B., Serpette, A., Dubert, J., 2013. Interactions of surface and deep anticyclonic eddies in the Bay of Biscay. Journal of Marine Systems 110, 45-59.

Casey, K., Brandon, T., Cornillon, P., Evans, R., 2010. The Past, Present and Future of the AVHRR Pathfinder SST Program. In: Barale, V., Gower, J., Alberotanza, L. (Eds.), Oceanography from Space: Revisited. Springer Netherlands, pp. 273-287.

Chelton, D. B., Schlax, M. G., Samelson, R. M., 2011. Global observations of nonlinear mesoscale eddies. Progress in Oceanography 91, 167-216.

D'Asaro, E., 1988. Generation of Submesoscale Vortices: A New Mechanism. Journal of Geophysical Research 93, 6685-6693.

Dong, C., Lin, X., Liu, Y., Nencioli, F., Chao, Y., Guan, Y., Chen, D., Dickey, T., McWilliams, J., 2012. Three-dimensional oceanic eddy analysis in the Southern California Bight from a numerical product. Journal of Geophysical Research 117, 1-17.

Dubert, J., 1998. Dynamique du Système de Courants vers le Pôle au Voisinage de la Pente Continentale à l'Ouest et au Nord de la Péninsule Ibérique. Ph.D. thesis, University of Bretagne Occidentale, available from the Department of Physics, University of Aveiro, Portugal. 
Fiúza, A., Hamman, M., Ambar, I., Díaz del Río, G., González, N., Cabanas, J., 1998. Water masses and their circulation off western Iberia during May 1993. Deep-Sea Research I 45, 1127-1160.

Friocourt, Y., Blanke, B., Drijfhout, S., Speich, S., 2008a. On the Dynamics of the Slope Current System along the West European Margin. Part II: Analytical Calculations and Numerical Simulations with Seasonal Forcing. Journal of Physical Oceanography 38, 2619-2638.

Friocourt, Y., Drijfhout, S., Blanke, B., 2008b. On the Dynamics of the Slope Current System along the West European Margin. Part I: Analytical Calculations and Numerical Simulations with Steady-State Forcing. Journal of Physical Oceanography 38, 2597-2618.

Friocourt, Y., Levier, B., Speich, S., Blanke, B. Drijfhout, S., 2007. A regional numerical ocean model of the circulation in the Bay of Biscay. Journal of Geophysical Research 112, C09008.

Frouin, R., Fiúza, A., Ambar, I., Boyd, T., 1990. Observations of a poleward surface current off the coasts of Portugal and Spain during winter. Journal of Geophysical Research 95 (C1), 679-691.

Garcia-Soto, C., Pingree, R., Valdés, L., 2002. Navidad development in the southern Bay of Biscay: Climate change and swoddy structure from remote sensing and in situ measurements. Journal of Geophysical Research 107, 28, doi:10.1029/2001JC001012.

Garfield, N., Collins, C., Paquette, R., Carter, E., 1999. Lagrangian Exploration of the California Undercurrent, 1992-95. Journal of Physical Oceanography 29, 560-583.

Haynes, R., Barton, E., Pilling, I., 1993. Development, persistence, and variability of upwelling filaments off the Atlantic coast of the Iberian Peninsula. Journal of Geophysical Research 98 (C12), 22681-22692.

Le Cann, B., Serpette, A., 2009. Intense warm and saline upper ocean inflow in the southern Bay of Biscay in autumn-winter 2006-2007. Continental Shelf Research 29, 1014-1025.

Martins, C., Hamann, M., Fiúza, A., 2002. Surface circulation in the Eastern North Atlantic, from drifters and altimetry. Journal of Geophysical Research 107 (C12), 3217, doi:10.1029/2000JC000345. 
McWilliams, J. C., 1985. Submesoscale, Coherent Vortices in the Ocean. Reviews of Geophysics 23, 165-182.

McWilliams, J. C., 2006. Fundamentals of Geophysical Fluid Dynamics. Cambridge University Press.

McWilliams, J. C., Flierl, G., 1979. On the Evolution of Isolated, Nonlinear Vortices. Journal of Physical Oceanography 9, 1155-1182.

Molemaker, M. J., McWilliams, J. C., Dewar, W. K., 2015. Submesoscale instability and generation of mesoscale anticyclones near a separation of the California Undercurrent. Journal of Physical Oceanography - in press 0,0 .

Nencioli, F., Dong, C., Dickey, T., Washburn, L., McWilliams, J., 2010. A vector geometry based eddy detection algorithm and its application to high-resolution numerical model products and high-frequency radar surface velocities in the Southern California Bight. Journal of Atmospheric and Oceanic Technology 27, 564-579.

Oliveira, P., Peliz, A., Dubert, J., Rosa, T., Santos, A., 2004. Winter geostrophic currents and eddies in the western Iberia coastal transition zone. Deep Sea Research I 51, 367-381.

Peliz, A., Boutov, D., Cardoso, R., Delgado, J., Soares, P., 2012. The Gulf of Cadiz-Alboran Sea sub-basin: Model setup, exchange and seasonal variability. Ocean Modelling 61, 49-67.

Peliz, A., Dubert, J., Haidvogel, D., 2003a. Subinertial response of a density driven eastern boundary poleward current to wind forcing. Journal of Physical Oceanography 33, 1633-1650.

Peliz, A., Dubert, J., Haidvogel, D., Le Cann, B., 2003b. Generation and unstable evolution of a density-driven eastern poleward current. Journal of Geophysical Research 108, 3268, doi:10.1029/2002JC001443.

Peliz, A., Dubert, J., Santos, A., Oliveira, P., Le Cann, B., 2005. Winter upper ocean circulation in the Western Iberian Basin - Fronts, Eddies and Poleward Flows: an overview. Deep Sea Research I 52, 621-646.

Peliz, A., Rosa, T. L., Santos, A. M. P., Pissarra, J. L., 2002. Fronts, jets, and counter flows in the Western Iberian upwelling system. Journal of Marine Systems 35, 61-77. 
Pingree, R., Le Cann, B., 1990. Structure, strength and seasonality of the slope currents in the Bay of Biscay region. Journal of the Marine Biology Association of U.K. 70, 857-885.

Pingree, R., Le Cann, B., 1992a. Anticyclonic eddy X91 in the southern Bay of Biscay, May 1991 to February 1992. Journal of Geophysical Research 97, 14353-14367.

Pingree, R., Le Cann, B., 1992b. Three anticyclonic Slope Water Oceanic eDDIES (SWODDIES) in the Southern Bay of Biscay in 1990. Deep-Sea Research I 39, 1147-1175.

Relvas, P., Barton, E., 2002. Mesoscale patterns in the Cape São Vicente (Iberian Peninsula) upwelling region. Journal of Geophysical Research 107, 3164, doi:10.1029/2000JC000456.

Rossi, V., Garçon, V., Tassel, J., Romagnan, J., Stemmann, L., Jourdin, F., Morin, P., Morel, Y., 2013. Cross-shelf variability in the Iberian Peninsula Upwelling System: Impact of a mesoscale filament. Continental Shelf Research 59, 97-114.

Serra, N., Ambar, I., Boutov, D., 2010. Surface expression of Mediterranean Water dipoles and their contribution to the shelf/slope - open ocean exchange. Ocean Science 6, 191-209.

Soares, P., Cardoso, R., Miranda, P., Medeiros, J., Belo-Pereira, M., Espirito-Santo, F., 2012. WRF high resolution dynamical downscaling of ERA-Interim for Portugal. Climate Dynamics 110.

Teles-Machado, A., Peliz, A., McWilliams, J. C., Cardoso, R. M., Soares, P. M. M., Miranda, P. M. A., 2015a. On the year-to-year changes of the Iberian Poleward Current. Journal of Geophysical Reserch 120, 49804999, doi:10.1002/2015JC010758.

Teles-Machado, A., Peliz, A., McWilliams, J. C., Couvelard, X., Ambar, I., 2015b. Circulation on the Northwestern Iberian Margin: Vertical structure and seasonality of the alongshore flows. Progress in Oceanography (in press),Doi:10.1016/j.pocean.2015.05.021.

Torres, R., Barton, E., 2006. Onset and development of the Iberian poleward flow along the Galician coast. Continental Shelf Research 26, 1134-1153. 